Revista Universo Contábil, ISSN 1809-3337
Blumenau, v. 16, n. 4, p. 27-49, out./dez., 2020

\title{
REVISITANDO A RENTABILIDADE DOS BANCOS BRASILEIROS: EVIDÊNCIAS DOS SOBREVIVENTES DA CRISE DE 2008 ANTES DO ATAQUE DAS FINTECHS
}

\section{REVISITING BRAZILIAN BANKS PROFITABILITY: EVIDENCE FROM 2008 CRISIS SURVIVORS BEFORE THE FINTECH ATTACK}

\section{REVISANDO LA RENTABILIDAD DE LOS BANCOS BRASILEÑOS: EVIDENCIA DE LOS SOBREVIVIENTES DE LA CRISIS DE 2008 ANTES DEL ATAQUE DE LAS FINTECHS}

Recebido em: 23-08-2018

Avaliado em: 03-05-2021

Reformulado em: 20-06-2021

Aceito para publicação em: 21-06-2021

Publicado em: 26-11-2021

Editor Responsável: Tarcísio Pedro da Silva

\author{
Carlos André Marinho Vieira ${ }^{1}$ \\ Luiz Felipe de Araújo Pontes Girão ${ }^{2}$
}

\section{RESUMO}

Nossa pesquisa teve por objetivo analisar os determinantes da rentabilidade dos bancos brasileiros no período de 1996 a 2015, analisando a influência de fatores específicos e macroeconômicos. Nossa amostra é composta por 106 bancos com dados semestrais disponíveis para todos os períodos analisados, com bancos que sobreviveram à Crise de 2008, mas antes de serem atacados pelas fintechs. Para tratar problemas de endogeneidade, foi feito o uso do estimador system-GMM. A rentabilidade bancária foi representada pelo Return on Assets (ROA) e Return on Equity (ROE), como complemento. Nossos resultados gerais indicaram que o ROA é influenciado positivamente pela eficiência, sendo negativamente influenciado pelo risco dos ativos bancários e pela diversificação das atividades. Dentre as variáveis macroeconômicas, a taxa de juros mostrou uma associação positiva com o ROA. O ROE mostrou-se muito mais sensível aos fatores macroeconômicos. Descobriu-se, ainda, que a competição, o crescimento econômico, a inflação e as taxas de juros exercem influência sobre a riqueza gerada para os proprietários dos bancos.

Palavras-chave: Rentabilidade bancária. Diversificação das receitas. Crise. Operações de crédito. Fintech.

\section{ABSTRACT}

Our study aimed to analyze the determinants of Brazilian banks' profitability between 1996 and 2015, analyzing the influence of specific and macroeconomic factors. Our sample consists of 106 banks

\footnotetext{
${ }^{1}$ Analista-Chefe do TC Traders Club S.A. Doutor em Ciências Contábeis pelo Programa de Pós-Graduação em Ciências Contábeis da Universidade Federal da Paraíba; E-mail: carlos.vieira@tc.com.br

${ }^{2}$ Diretor Educacional e de Pesquisa \& Desenvolvimento do TC Traders Club S.A. Doutor em Ciências Contábeis pelo Programa Multiinstitucional e Inter-regional de Pós-Graduação em Contabilidade UnB/UFPB/UFRN.; E-mail: felipe.pontes@tc.com.br
} 
with semiannual data for all periods analyzed, with banks that survived the 2008 Crisis before being attacked by fintech. To treat endogeneity problems, the system-GMM estimator was used. Banking profitability was represented by Return on Assets (ROA) and Return on Equity (ROE) as a complement. Our general results indicated that ROA is positively influenced by efficiency, negatively influenced by the risk of banking assets, and the diversification of activities. Among the macroeconomic variables, the interest rate showed a positive association with ROA. ROE proved to be much more sensitive to macroeconomic factors. It was also discovered that competition, economic growth, inflation, and interest rates influence the wealth generated for bank owners.

Keywords: Bank profitability. Diversification. Crisis. Bank loans. Fintech.

\section{RESUMEN}

Nuestra investigación tuvo como objetivo analizar los determinantes de la rentabilidad de los bancos brasileños en el período de 1996 a 2015, analizando la influencia de factores específicos y macroeconómicos. Nuestra muestra está formada por 106 bancos con datos semestrales disponibles para todos los períodos analizados, con bancos que sobrevivieron a la Crisis de 2008, pero antes de ser atacados por fintechs. Para tratar los problemas de endogeneidad se utilizó el estimador de sistema-GMM. La rentabilidad bancaria estuvo representada por Return on Assets (ROA) y Return on Equity (ROE), como complemento. Nuestros resultados generales indicaron que el ROA está influenciado positivamente por la eficiencia, siendo influenciado negativamente por el riesgo de los activos bancarios y la diversificación de actividades. Entre las variables macroeconómicas, la tasa de interés mostró una asociación positiva con el ROA. El ROE demostró ser mucho más sensible a los factores macroeconómicos. También se descubrió que la competencia, el crecimiento económico, la inflación y las tasas de interés influyen en la riqueza generada para los propietarios de bancos.

Palabras-clave: Rentabilidad bancaria. Diversificación de los ingresos. Crisis. Operaciones de crédito. Fintech.

\section{INTRODUÇÃO}

Nosso objetivo nesta pesquisa é analisar, com uma abordagem diferente, os fatores determinantes da rentabilidade dos bancos brasileiros. A motivação para o desenvolvimento desta pesquisa se dá porque o sistema financeiro brasileiro é um dos mais regulados e seguros do mundo e toda esta segurança tem um custo: concentração em poucas instituições financeiras, gerando uma distorção nos fundamentos dos bancos participantes do mercado brasileiro.

Os bancos listados ao redor do mundo seguem um padrão de rentabilidade diferente dos bancos listados no Brasil. Com dados da Economatica, é possível observar que há mais de uma década os bancos brasileiros têm as maiores rentabilidades entre os seus pares no mundo, com Return on Equity (ROE) sempre próximo ou acima de 20\%, enquanto nos EUA eles ficam próximos dos $10 \%$ muitas vezes até abaixo.

Todavia, os grandes bancos brasileiros acabaram por começar a sentir os efeitos do aumento da competição e disrupção no setor, com a chegada e o fortalecimento das fintechs. Adicionalmente, as crises financeiras que afetaram o mundo inteiro a partir do final dos anos 2000 têm aumentado a demanda por pesquisas sobre como essas instituições operam e quais são os riscos advindos da sua má gestão para a sociedade. Assim, entender o que afeta a rentabilidade dos bancos antes do processo de disrupção causado pelas fintechs estar completo e antes da chegada de uma nova crise de impacto global poderá ser útil para entender também como as fintechs poderiam se tornar lucrativas, reduzindo o risco de default sistêmico com o seu crescimento.

Apesar da importância da rentabilidade e da lucratividade bancária como determinante para o bom funcionamento do sistema financeiro de um país, as pesquisas concentram-se principalmente em 
amostras de países desenvolvidos, como Estados Unidos da América (EUA) e aqueles da Europa (Albertazzi \& Gambacorta, 2009; Elsas, Hackethal, \& Holzhäuser, 2010; Hoffmann, 2011; Dietrich \& Wanzenried, 2011; Trujillo-Ponce, 2013). A maioria dos estudos em países emergentes focam principalmente naqueles localizados no continente asiático (García-Herrero, Gavilá, \& Santabárbara, 2009; Lee \& Hsieh, 2013), havendo poucas evidências de estudos no mercado financeiro brasileiro (Tabak, Fazio, \& Cajueiro, 2011; Dantas, Medeiros, \& Paulo, 2011; Rover, Tomazzia, \& Fávero, 2013; Vinhado \& Divino, 2013; Primo, Dantas, Medeiros, \& Capelletto, 2013).

Pela sua importância no bem-estar social, dado que os bancos são os principais intermediários financeiros, e pela sua relevância na economia nacional, é importante que se analise como estas instituições operam e como evitar as consequências negativas de seu mau funcionamento, entendendo quais fatores de fato são mais importantes para mantê-las rentáveis.

Neste contexto, o Brasil oferece uma interessante opção para o estudo da rentabilidade das instituições financeiras por várias razões. Primeiramente, apresenta-se como o maior país da América do Sul em extensão e em Produto Interno Bruto (PIB), financiando várias economias de países vizinhos. O segundo ponto é que a economia local é caracterizada por uma forte influência governamental no sistema financeiro, com significativa importância dos bancos estatais no fornecimento de crédito para alguns setores vitais da economia, como o agronegócio, o consumo cíclico e o setor imobiliário. Por fim, as altas taxas de juros praticadas historicamente no país contrastam com aquelas praticadas em países desenvolvidos, sobretudo EUA, Japão e países Europeus, que experimentam taxas básicas de juros próximas a zero e até mesmo negativas em termos reais.

Desta forma, para atingir o objetivo da pesquisa, nossa amostra é composta por todas as instituições financeiras brasileiras classificadas como bancos, que tinham dados disponíveis entre 1996 e 2015 - antes do início da expansão das fintechs e da normalização das taxas de juros. Isso implica dizer que trabalhamos com um painel balanceado de dados, com 38 semestres para cada um dos bancos que compuseram a amostra final. Dependendo da proxy para rentabilidade, trabalhamos com 98 ou 106 bancos, de capital aberto ou não.

O encerramento do período em 2015 serve justamente para pegar o último ano antes do boom de fintechs no Brasil, que receberam mais de US\$ 2 bi de investimentos, entre 2015 e 2021 (Consumidor Moderno, 2021), e que vêm focando seus esforços nas principais atividades dos bancos tradicionais (Larghi, 2020), que fazem com que eles estejam entre os mais rentáveis do mundo. Ainda, no geral, os bancos tradicionais se beneficiam das taxas de juros mais altas e este período escolhido é anterior ao período de reduções bruscas que ocorreram na taxa básica de juros do Brasil - a Selic.

Como variáveis representativas da rentabilidade bancária, escolhemos utilizar o Return on Equity (ROE) e o Return on Assets (ROA). Para tratar eventuais problemas de endogenia, utilizamos o System-GMM, com estimador de dois estágios e com correção de Windmeijer para amostras finitas, para lidar com possível subestimação dos erros-padrão.

Comparando especialmente com outras pesquisas semelhantes e que foram publicadas com dados brasileiros, nossa pesquisa se diferencia das demais no seguinte sentido: notamos que elas têm focado nos impactos que a rentabilidade dos bancos sofre por meio da diversificação da carteira de crédito (Tabak et al., 2011), variáveis econômico-financeiras e macroeconômicas no geral (Rover et al., 2013; Vinhado \& Divino, 2013; Primo et al., 2013; Ciganda, 2020), investimentos em tecnologia (Barreto, Pereira \& Penedo, 2021), assim como a concentração do mercado (Dantas et al., 2011; Vinhado \& Divino, 2013; Pereira, 2019) que é uma das nossas principais variáveis específicas dos bancos que buscam explicar a sua rentabilidade. Nós exploramos questões semelhantes, mas também outras implicações adicionais.

Metodologicamente, esta pesquisa também se diferencia das demais já realizadas no Brasil. Especificamente, comparando com as pesquisas que consideraram o fator concentração/competição no mercado bancário como um fator determinante da rentabilidade, Dantas et al. (2011) trabalharam com dados mensais entre 2000 e 2009, Vinhado e Divino (2013) usaram uma amostra de dados 
trimestrais entre 2000 e 2008, enquanto Pereira (2019) teve uma amostra com dados trimestrais entre 2000 e 2019. Nós usamos dados semestrais de 1996 a 2015, passando pela Crise de 2008 de modo a avaliar os seus impactos interativos com outras variáveis importantes e já destacadas na literatura desta área de pesquisa.

Dantas et al. (2011) apresentaram evidências de que a concentração no mercado bancário começou a crescer a partir de 2008. Como a amostra daquela pesquisa foi encerrada em 2009, eles não conseguiram captar por completo o efeito do aumento da concentração bancária na rentabilidade dos bancos, assim como Vinhedo e Divino (2013) também não conseguiram. Nossa pesquisa consegue captar melhor o efeito pós-Crise de 2008, com os testes de sensibilidade evidenciando que a concentração de ativos passou a impactar mais negativamente a rentabilidade dos bancos brasileiros nos anos após a Crise.

Com relação ao modelo de estimação para atingir o objetivo da pesquisa, Dantas et al. (2011) não utilizaram o System GMM, o que pode fazer com que os seus resultados possam estar viesados e sejam inconsistentes. Vinhado e Divino (2013) utilizaram o System GMM, porém a sua proxy para concentração de mercado foi um percentual de ativos do banco em relação ao total de ativos do sistema financeiro nacional, que não considera o tamanho dos bancos - diferente do Índice de Herfindahl-Hirschman, utilizado nesta pesquisa. Pereira (2019) fez escolhas metodológicas mais próximas às que utilizamos nesta pesquisa para a estimação dos modelos e para o cálculo da concentração de mercado, todavia não houve a consideração da diversificação de receitas.

Ainda no sentido de nos diferenciar metodologicamente de outras pesquisas publicadas com dados de bancos brasileiros, nosso trabalho se diferencia também da pesquisa de Ferreira, Zanini e Alves (2019). Os autores fizeram uma análise completa em relação ao impacto da diversificação das receitas não só na rentabilidade dos bancos, mas também no risco daquelas instituições - neste caso, semelhante ao trabalho de Vieira e Girão (2016).

Por termos considerado nesta pesquisa as principais variáveis que, teoricamente, em conjunto, são determinantes da rentabilidade dos bancos, nossa pesquisa acrescenta mais peças ao quebracabeça dos fatores determinantes da rentabilidade bancária no Brasil, como sendo um caso especial. Ferreira et al. (2019), apesar de terem considerado a diversificação de receitas, não consideraram o fato de que o setor bancário brasileiro é muito concentrado em poucos e grandes bancos.

Adicionalmente, a amostra usada por Ferreira et al. (2019) é mais restrita, compreendendo dados anuais de 2003 a 2014, com painéis de dados desbalanceados, excluindo-se os bancos com PL negativo, inclusive para o cálculo do ROA e com tratamento de outliers por meio da técnica de winsorização a $3 \%$. Em conjunto, essas características, mais uma vez, fazem com que os resultados da pesquisa em tela tragam de fato mais uma peça relevante para que possamos entender melhor a rentabilidade dos bancos brasileiros.

Nossos testes de sensibilidade indicaram que quando há maior concentração bancária em termos de depósitos e crédito, os bancos médios são negativamente impactados em termos de rentabilidade. Ainda, quando há muita concentração bancária em termos de ativos e depósitos, os bancos médios mais eficientes conseguem ter rentabilidades melhores que os demais bancos.

De forma geral, nossos principais resultados indicaram que o ROA é influenciado positivamente pela eficiência dos bancos, sendo negativamente influenciado pelo risco dos ativos bancários e pela diversificação das atividades. É interessante notar, ainda, que os bancos mais eficientes tendem a ter ROEs e ROAs maiores, indicando que pode haver um comportamento esperado semelhante nas fintechs, quando chegarem a uma fase mais madura, mas que também os bancos mais eficientes podem estar melhor preparados para o processo de disrupção que foi essencialmente acelerado após 2015 no Brasil.

Dentre as variáveis macroeconômicas, a taxa de juros mostrou uma associação positiva com o ROE e ROA. É importante destacar que o ROE se mostrou muito mais sensível aos fatores macroeconômicos do que o ROA. Este resultado é interessante para a política do atual Banco Central do Brasil que quer estimular a competição e para as pessoas em geral, dado que apenas o ROE foi 
impactado por fatores como concentração no setor, crescimento econômico e inflação. Sendo assim, fatores macroeconômicos utilizados nesta pesquisa pouco influenciam o desempenho geral dos bancos (medido pelo ROA), mas afetam diretamente a "riqueza" gerada para os donos do capital dos bancos (medido pelo ROE), corroborando a fundamental importância de se analisar os impactos do aumento da competição e melhorias no ambiente macroeconômico brasileiro para a disseminação das fintechs como ferramentas para melhorar o sistema bancário brasileiro.

O restante do trabalho está dividido da seguinte forma: seção 2 de revisão da literatura, seção 3 com o detalhamento da metodologia utilizada, seção 4 com os resultados e a seção 5 encerra o trabalho com as considerações finais.

\section{HISTÓRICO REGULATÓRIO DOS BANCOS BRASILEIROS E PRINCIPAIS FATORES DETERMINANTES DO DESEMPENHO DOS BANCOS}

As tentativas do governo brasileiro de regulamentar e aumentar a eficiência do setor bancário foram muitas ao longo dos tempos. A Lei no 4.595 de 1964, conhecida como Lei da Reforma Bancária, é uma das reformas do sistema bancário mais relevantes. Essa lei criou o Conselho Monetário Nacional (CMN) e o Banco Central do Brasil (BCB), que passaram a exercer os papéis de entidades normativa e fiscalizadora, respectivamente. Anos depois, a Resolução do CMN $\mathrm{n}^{\circ} 1.524$ de 21/09/1988 criou a figura dos bancos múltiplos e incentivou a fusão de outros tipos de instituições financeiras em bancos múltiplos, criando economias de escala para a atuação de várias instituições em diversos ramos de negócios, registradas sob a forma de uma só entidade.

Porém, a estabilização da economia e a redução da inflação a partir do início da década de 1990, em conjunto, diminuíram as receitas dos bancos, principalmente aquelas originárias de floating. A intervenção governamental foi marcada por diversos programas de reestruturação do sistema financeiro nacional, além da abertura da economia ao investimento estrangeiro nas instituições financeiras que operam sobre o território nacional, tornando as instituições mais fortes e mais abrangentes em todo o Brasil.

Apesar de fatores que ampliaram a escala e escopo das operações bancárias, os riscos assumidos por estas instituições resultaram na adoção, pelo Banco Central do Brasil, dos denominados Acordos de Basileia I (1988), II (2004) e III, este último adotado no Brasil a partir de 2011. Os Acordos de Basileia têm por objetivo a manutenção de um adequado nível de ativos de alta liquidez e de reservas de capital que protejam as instituições em caso de dificuldades financeiras (Dietrich, Hess, \& Wanzenried, 2014).

Neste sentido, diversas pesquisas empíricas têm analisado a influência dos fatores determinantes do desempenho dos bancos, medido pela sua rentabilidade/lucratividade e eficiência operacional. De acordo com os principais trabalhos, os fatores determinantes da rentabilidade/lucratividade bancária são classificados em dois grandes grupos: a) fatores individuais/específicos de cada banco; e b) fatores macroeconômicos e regulatórios. Os fatores específicos de cada banco são resultado de decisões gerenciais sobre a estrutura dos ativos, sua qualidade, setores de atuação, eficiência, alavancagem financeira e operacional. Os fatores macroeconômicos e regulatórios estão relacionados com o sistema financeiro em que os bancos operam e levam em consideração a variação do Produto Interno Bruto (PIB), inflação, taxa de juros básica e competição (Dietrich \& Wanzenried, 2011; Rover et al., 2013; Trujillo-Ponce, 2013; Vinhado \& Divino, 2013). Na Tabela 1 são listados os principais estudos com destaque para sua amostra e principais resultados. 
REVISITANDO A RENTABILIDADE DOS BANCOS BRASILEIROS: EVIDÊNCIAS DOS SOBREVIVENTES DA CRISE DE 2008 ANTES DO ATAQUE DAS FINTECHS

\section{Tabela 1}

Principais estudos sobre a rentabilidade bancária no Brasil e no mundo e seus principais resultados

\begin{tabular}{|c|c|c|c|}
\hline Autores (Ano) & Período & Países & Principais resultados \\
\hline Primo et al. (2013) & 2000-2009 & Brasil & $\begin{array}{l}\text { A taxa básica de juros da economia, o crescimento econômico } \\
\text { e a eficiência operacional influenciam positivamente a } \\
\text { rentabilidade bancária. }\end{array}$ \\
\hline Lee e Hsieh (2013) & 1994-2008 & $\begin{array}{l}42 \text { países } \\
\text { asiáticos }\end{array}$ & $\begin{array}{l}\text { A capitalização bancária impacta positivamente a } \\
\text { rentabilidade. Este impacto é diferente dependendo do país de } \\
\text { origem da instituição. }\end{array}$ \\
\hline $\begin{array}{l}\text { Mirzaei, Moore e } \\
\quad \text { Liu (2013) }\end{array}$ & 1999-2008 & 40 países & $\begin{array}{l}\text { Um elevado market share está relacionado com maior } \\
\text { lucratividade nos países desenvolvidos. Esta relação não é } \\
\text { observada nos países em desenvolvimento. }\end{array}$ \\
\hline Rover et al. (2013) & 1995-2009 & Brasil & $\begin{array}{l}\text { A eficiência operacional, a capitalização, o crescimento da } \\
\text { atividade econômica, a inflação e a taxa básica de juros estão } \\
\text { positivamente relacionados com a lucratividade; } \\
\text { O volume de reservas para saques, o volume de despesas } \\
\text { operacionais e a má qualidade do crédito estão negativamente } \\
\text { relacionados com a lucratividade. }\end{array}$ \\
\hline $\begin{array}{l}\text { Vinhado e Divino } \\
\qquad(2013)\end{array}$ & $2000-2008$ & Brasil & $\begin{array}{l}\text { Os bancos privados nacionais mostraram-se mais rentáveis. Os } \\
\text { conglomerados e bancos listados em bolsa apresentam menor } \\
\text { rentabilidade; } \\
\text { As operações de fusões e aquisições só impactam } \\
\text { positivamente os lucros a partir do segundo ano após o } \\
\text { negócio; } \\
\text { O tamanho dos bancos, os níveis de crescimento econômico, } \\
\text { taxas de juros e inflação impactam positivamente na } \\
\text { rentabilidade. }\end{array}$ \\
\hline $\begin{array}{l}\text { Trujillo-Ponce } \\
\qquad(2013)\end{array}$ & 1999-2009 & Espanha & $\begin{array}{l}\text { O alto percentual de empréstimos realizados e depósitos } \\
\text { captados, a eficiência, a qualidade dos ativos, o nível de } \\
\text { capitalização e o tamanho das instituições estão positivamente } \\
\text { relacionados com a lucratividade. }\end{array}$ \\
\hline Chen e Liao (2011) & 1992-2006 & 70 países & $\begin{array}{l}\text { Bancos estrangeiros apresentam maior lucratividade que } \\
\text { bancos domésticos quando operam em países onde o setor } \\
\text { bancário é menos competitivo. }\end{array}$ \\
\hline $\begin{array}{c}\text { Dietrich e } \\
\text { Wanzenried (2011) }\end{array}$ & 1999-2009 & Suécia & $\begin{array}{l}\text { A eficiência, o crescimento das aplicações em empréstimos e a } \\
\text { diversificação de receitas está relacionado positivamente com } \\
\text { a lucratividade. }\end{array}$ \\
\hline Hoffman (2011) & $1995-2007$ & $\begin{array}{l}\text { Estados } \\
\text { Unidos }\end{array}$ & $\begin{array}{l}\text { A capitalização bancária e o tamanho das instituições estão } \\
\text { negativamente relacionados com a lucratividade. }\end{array}$ \\
\hline Tabak et al. (2011) & 2003-2009 & Brasil & $\begin{array}{l}\text { A concentração do portfólio de empréstimos aumenta o retorno } \\
\text { e reduz o risco de falência das instituições financeiras. }\end{array}$ \\
\hline Elsas et al. (2010) & 1996-2008 & $\begin{array}{l}\text { América do } \\
\text { Norte, Europa } \\
\text { e Austrália }\end{array}$ & $\begin{array}{l}\text { A diversificação advinda do crescimento orgânico da } \\
\text { instituição ou de políticas de fusões e aquisições aumenta a } \\
\text { lucratividade. }\end{array}$ \\
\hline $\begin{array}{c}\text { Albertazzi e } \\
\text { Gambacorta (2009) }\end{array}$ & $1981-2003$ & EUA e Europa & $\begin{array}{l}\text { Bancos localizados nos Estados Unidos e Reino Unido } \\
\text { apresentam maior lucratividade que suas contrapartes na } \\
\text { Europa. }\end{array}$ \\
\hline $\begin{array}{l}\text { García-Herrero et } \\
\text { al. (2009) }\end{array}$ & 1997-2004 & China & $\begin{array}{l}\text { Bancos mais capitalizados são mais lucrativos, assim como os } \\
\text { bancos com maior volume de depósitos e maior eficiência. } \\
\text { Quanto maior a concentração bancária maior a lucratividade } \\
\text { destas instituições. }\end{array}$ \\
\hline
\end{tabular}

Fonte: Elaboração Própria. 


\section{PROCEDIMENTOS METODOLÓGICOS}

\subsection{População, Amostra e Dados}

A população do estudo é composta por todas as instituições financeiras brasileiras classificadas como bancos no sítio eletrônico do Banco Central do Brasil (BCB) (www.bcb.gov.br), analisadas do segundo semestre de 1996 ao primeiro semestre de 2015. O encerramento do período em 2015 serve justamente para pegar o último ano antes do boom de fintechs no Brasil e antes da normalização da taxa de juros.

Dados relativos à variação do PIB e do IPCA foram coletados através do site do Instituto Brasileiro de Geografia e Estatística (www.ibge.gov.br). A variação da taxa Selic foi obtida também através do sítio eletrônico do BCB. As variáveis utilizadas na pesquisa, detalhadas na próxima seção, são calculadas por acumulações semestrais (ROA, ROE, Efficiency, Diversification, Concentration, EconGrowth, Inflation, IRates) ou ao final de cada semestre (Loans/Assets, ADC/Assets, Debt/Assets, DepTot, Size).

Para a construção de um painel balanceado foram eliminados da amostra todos os bancos com menos de 38 observações, correspondentes aos 38 semestres estudados. Adicionalmente, quando o ROE foi utilizado como variável dependente, foram eliminados também os bancos que apresentaram patrimônio líquido negativo. Para os modelos de regressão que utilizaram o ROA como variável dependente foram obtidas 4.028 observações de 106 bancos. Para os modelos de regressão que utilizaram o ROE como variável dependente foram obtidas 3.724 observações de 98 bancos. Foram analisados apenas os balancetes individuais dos bancos.

\subsection{Variáveis utilizadas e estatísticas descritivas}

\subsubsection{Definição das variáveis utilizadas na pesquisa}

\section{(A) Proxies de desempenho dos bancos (variável dependente)}

Como proxy para a rentabilidade dos bancos, utilizamos o Return on Assets (ROA) e Return on Equity (ROE), que são as variáveis dependentes do modelo econométrico. O ROA e o ROE são duas medidas amplamente utilizadas em estudos na área de finanças bancárias (García-Herrero et al., 2009; Albertazzi \& Gambacorta, 2009; Elsas et al., 2010; Dantas et al., 2011; Dietrich \& Wanzenried, 2011; Tabak et al., 2011; Chen \& Liao, 2011; Mirzaei et al., 2013; Rover et al., 2013; Trujillo-Ponce, 2013; Lee \& Hsieh, 2013; Vinhado \& Divino, 2013; Dietrich et al., 2014). Ambas as medidas de desempenho utilizam o lucro antes dos itens extraordinários como numerador em relação ao ativo total e patrimônio líquido, respectivamente.

Nas subseções a seguir explicaremos quais são as variáveis independentes da pesquisa, que estão divididas em dois grupos. O primeiro grupo é composto por características econômicofinanceiras específicas das instituições financeiras que compuseram a amostra, enquanto o segundo grupo de variáveis é composto por fatores macroeconômicos.

\section{(B) Proxies para as características específicas dos bancos (variáveis independentes)}

Loans/Assets: Capta a importância das operações de empréstimo em relação aos outros ativos bancários. Apesar destas aplicações apresentarem baixa liquidez e demandarem custos de monitoração, elas originaram altas receitas com juros, o que tem capacidade de aumentar a rentabilidade das instituições financeiras (García-Herrero et al., 2009; Trujillo-Ponce, 2013). A estrutura dos ativos é representada pela razão entre as operações de crédito ativas (empréstimos) e os ativos totais. 
Quality = ADC/Assets: A qualidade dos ativos é representada pela razão entre a provisão para operações de crédito em relação aos ativos. Espera-se que a qualidade dos ativos represente o risco de crédito ao qual os bancos estão expostos. A literatura aponta vários argumentos para que seja esperada uma relação positiva ou negativa entre a qualidade dos ativos e a rentabilidade dos bancos. Se por um lado os bancos devem provisionar maiores montantes para cobrir perdas de operações de crédito mais arriscadas, eles podem cobrar juros mais altos por estas operações, o que aumentaria sua rentabilidade (Rover et al., 2013; Trujillo-Ponce, 2013). Então, o efeito esperado dependerá da qualidade do controle de risco que o banco fizer.

Debt/Assets: O nível de endividamento é calculado pela razão entre os passivos exigíveis e os ativos totais. Um alto endividamento pode ser vantajoso à empresa pelo benefício físcal da dedutibilidade dos juros no pagamento de impostos, bem como pelo maior monitoramento da atividade bancária por parte dos credores, o que levaria a uma maior busca por melhor desempenho. Por outro lado, o aumento da dívida gera também o aumento do risco de falência e dos custos de agência originários do conflito de interesses entre credores e acionistas (Dietrich \& Wanzenried, 2011; Hoffmann, 2011; Rover et al., 2013), o que nós entendemos que afeta muito mais o custo do capital do que a rentabilidade per se. Apesar de a maioria dos trabalhos utilizarem a razão entre o patrimônio líquido e os ativos totais como medida de capitalização/endividamento (Chen \& Liao, 2011; Dietrich \& Wanzenried, 2011; Hoffmann, 2011; Lee \& Hsieh, 2013; Mirzaei et al., 2013; Rover et al., 2013; Trujillo-Ponce, 2013; Dietrich et al., 2014), fizemos uso da medida inversa, uma vez que a outra medida pode apresentar valores negativos, o que pode comprometer a forma linear da análise.

DepTot: Esta variável deriva da relação entre os depósitos e as outras formas de captação de recursos, indicando a proporção dos passivos exigíveis financiada por meio de depósitos de clientes. A forma como o banco capta recursos para financiar seu capital afeta consideravelmente seus resultados. Bancos que financiam suas atividades através de depósitos de clientes apresentam um menor custo de captação, uma vez que, em muitos países como o Brasil, estes depósitos estão assegurados por algum órgão privado ou governamental (Trujillo-Ponce, 2013). Ao considerar que os depósitos de clientes são formas mais baratas de captação que outros meios alternativos, uma grande proporção de depósitos em relação às outras fontes de financiamento estaria ligada a um menor custo das atividades bancárias e maior rentabilidade.

Efficiency: Os avanços nas áreas financeira e informacional têm permitido aos bancos aumentar o escopo de suas operações e prestar seus serviços de maneira mais eficiente. Quanto menores os custos operacionais em relação às receitas auferidas em um mesmo período, mais eficiente é uma instituição e, consequentemente, maior será o retorno esperado para seus acionistas. Representamos a eficiência da atividade bancária pela relação entre as despesas totais e as receitas totais de um mesmo período, sendo esperada uma relação negativa entre a proxy eficiência e a rentabilidade (Albertazzi \& Gambacorta, 2009; Rover et al., 2013; Trujillo-Ponce, 2013), dado que quanto maior for este número, menos eficiente será o banco.

Size, LogAssets, Small e Large: Na literatura de finanças, há diversas interpretações sobre a relação existente entre o tamanho dos bancos e a sua rentabilidade. Alguns autores sugerem uma relação linear, em que quanto maior for a instituição financeira, maior será o seu poder para auferir receitas e, consequentemente, maior será o seu retorno (Rover et al., 2013). Desta forma, a variável LogAssets tenta capturar esta relação e é medida pelo logaritmo dos ativos totais (Assets) deflacionados. Outros autores argumentam que existe uma relação em forma de " $u$ " invertido $(\cap)$, de modo que os bancos médios apresentam maior rentabilidade que os bancos grandes e pequenos (Trujillo-Ponce, 2013). Para testar esta hipótese, utilizamos variáveis dummies para representar bancos pequenos (Small) e grandes (Large), cuja expectativa é que tenham impacto negativo na rentabilidade. Essas variáveis representam, respectivamente, bancos que possuem ativos correspondentes ao $1^{\circ}$ e ao $4^{\circ}$ quartil da distribuição (abaixo do percentil $25^{\circ}$ e acima do percentil $75^{\circ}$, respectivamente). 
Diversification: A exploração de vários ramos de negócios pode contribuir para a estabilização da rentabilidade bancária (Albertazzi \& Gambacorta, 2009). As vantagens da diversificação incluem economias de escopo, melhora na alocação de recursos e vantagem competitiva. Por outro lado, os custos associados à diversificação das atividades englobam desde problemas de agência, decorrentes da decisão de diversificar, e utilização ineficiente dos recursos pela administração da empresa. Além disso, muitas instituições podem começar a operar em setores nos quais não possuem experiência e know-how apropriados, gerando prejuízos para os acionistas (Elsas et al., 2010; Trujillo-Ponce, 2013). Sendo assim, esperamos uma relação negativa entre a rentabilidade da empresa e a diversificação das receitas.

A diversificação é representada por uma variável derivada do Índice Herfindahl-Hirschman (IHH). O IHH é calculado pelo quadrado do percentual de cada tipo de receita (Rev) auferida pelos bancos em relação às receitas totais (Tot) em um dado período. As receitas são classificadas de acordo com o Plano Contábil das Instituições do Sistema Financeiro Nacional (COSIF). Este índice é modificado pela subtração do número 1, fazendo com que quanto maior for o valor desta variável, maior será a diversificação das receitas do banco.

\section{(C) Proxies para características macroeconômicas e do mercado em geral (variáveis independentes)}

Concentration: Ambientes menos concentrados e mais competitivos geram consequências como uma diminuição dos juros cobrados de clientes ou aumento dos juros pagos para os depositantes, que resultam em uma menor rentabilidade geral do sistema financeiro. Ao mesmo tempo, a alta concentração pode gerar maior eficiência para as instituições sobreviventes, uma vez que é necessário um maior esforço para que os bancos possam competir em um mercado cada vez mais exigente (Trujillo-Ponce, 2013). As principais evidências apontam para uma relação negativa entre a competição e a rentabilidade dos bancos. A concentração é medida pelo somatório do quadrado dos ativos (IHHAssets), depósitos (IHHDep) ou operações de crédito (IHHCred) de cada instituição em relação ao total do setor em determinado ano. Quanto maior o índice, menor será a diversificação do mercado.

EconGrowth: Crises financeiras, recessões e outras condições econômicas negativas diminuem a demanda por crédito, aumentam a volatilidade dos mercados e o risco das operações, levando a perdas mais altas por inadimplência. As situações descritas acima têm um impacto considerável na rentabilidade bancária. A melhora do ambiente econômico geralmente tem um impacto positivo no setor financeiro (Dietrich et al., 2014, Trujillo-Ponce, 2013; Primo et al., 2013). $\mathrm{O}$ crescimento econômico é mensurado pela variação percentual real no PIB e nós esperamos um efeito positivo do ambiente econômico na rentabilidade dos bancos.

Inflation: Em países com altos níveis de inflação, como é o caso histórico do Brasil, estes custos invisíveis são repassados para os clientes em forma de taxas de empréstimos e serviços mais altas. O efeito da inflação na rentabilidade vai depender de como ela afeta os salários e outros custos operacionais. Caso os bancos não antecipem os efeitos da inflação nas suas atividades, há a possibilidade de que os custos cresçam de maneira mais rápida que as receitas (Lee \& Hsieh, 2013; Trujillo-Ponce, 2013; Primo et al., 2013). Sendo assim, como não há como saber, a priori, se os diferentes bancos estão usando estratégias diferentes, não estabelecemos uma relação esperada para esta variável. A variável inflação é representada pela variação percentual semestral do Índice de Preços ao Consumidor Amplo (IPCA).

IRate: A literatura especializada em estudos bancários apresenta diversas evidências sobre a influência da taxa básica de juros da economia no desempenho dos bancos. Ambientes com baixas taxas de juros podem acirrar a competição entre os bancos, limitando a possibilidade de elevação de preços para os produtos fornecidos. Por outro lado, altas taxas de juros podem elevar a rentabilidade destas instituições, uma vez que os bancos podem obter maiores retornos pela aplicação dos seus recursos (Primo et al., 2013). Como no Brasil há uma concentração bancária severa em poucos 
grandes bancos, nós assumimos que o aumento na taxa de juros tenha impacto positivo na rentabilidade dos bancos brasileiros, pois há muita concentração em poucos bancos (espécie de oligopólio) que facilita cobrar mais caro dos clientes sem maiores problemas de competição. Como disse o Ministro da Economia Paulo Guedes, em maio de 2019: "somos 200 milhões de patos e cinco bancos". A taxa básica de juros da economia foi representada nesta pesquisa pela variação semestral da taxa Selic.

\subsubsection{Estatísticas descritivas}

Para começar a entender as relações entre as variáveis e suas potenciais implicações, é importante entender a estrutura dos dados e efetuar uma análise exploratória. A seguir é possível compreender a estrutura dos dados com as estatísticas descritivas e com uma análise exploratória mais inicial.

\section{(A) Estatísticas descritivas}

Na Tabela 2 são evidenciados os valores da média, mediana, desvio-padrão, máximo e mínimo das principais variáveis utilizadas no estudo. O ROA médio para a amostra é de $0,375 \%$, próximo aos $0,343 \%$ observados por Rover et al. (2013), mas contrastam com os valores médios de $1,11 \%$ obtido por Primo et al. (2013) e 1,77\% de Ferreira et al. (2019). A média do ROE de 6,486\% é inferior ao ROE médio das instituições financeiras americanas (20,256\%), mas similar ao dos bancos espanhóis $(14,258 \%)$, se for considerada a média em bases anuais (Hoffmann, 2011, Trujillo-Ponce, 2013). Vale destacar que as outras pesquisas neste tema costumam "excluir" os outliers de diversas formas, o que não foi feito nesta pesquisa.

\section{Tabela 2}

\section{Estatísticas descritivas}

\begin{tabular}{|c|c|c|c|c|c|c|}
\hline Variáveis & Média & Mediana & Desvio-Pad. & Máximo & Mínimo & Obs \\
\hline $\mathrm{ROA}$ & 0,00375 & 0,00180 & 0,02029 & 0,43825 & $-0,34647$ & 4028 \\
\hline ROE & 0,06486 & 0,05632 & 0,24868 & 4,06641 & $-9,13244$ & 3724 \\
\hline Loans/Assets & 0,08739 & 0,05853 & 0,09188 & 0,66748 & 0,00000 & 4028 \\
\hline ADC/Assets & 0,00485 & 0,00182 & 0,01583 & 0,59574 & 0,00000 & 4028 \\
\hline Debt/Assets & 0,91237 & 0,96332 & 0,14526 & 1,54585 & 0,06443 & 4028 \\
\hline DepTot & 0,42869 & 0,40710 & 0,30686 & 0,99989 & 0,00000 & 4028 \\
\hline Efficiency & 0,91012 & 0,93757 & 0,34423 & 12,66673 & 0,00791 & 4028 \\
\hline Assets (bilhões R\$) & 161,133 & 6,017 & 671,086 & $8.752,963$ & 0,013 & 4028 \\
\hline Diversification & 0,54605 & 0,58527 & 0,18529 & 0,84206 & 0,00003 & 4028 \\
\hline IHHAssets & 0,11111 & 0,10102 & 0,04981 & 0,19824 & 0,04956 & 4028 \\
\hline IHHDep & 0,08627 & 0,08486 & 0,00926 & 0,11645 & 0,07389 & 4028 \\
\hline IHHCred & 0,08149 & 0,07604 & 0,01620 & 0,11823 & 0,05707 & 4028 \\
\hline EconGrowth & 0,02091 & 0,02227 & 0,04377 & 0,11817 & $-0,05869$ & 4028 \\
\hline Inflation & 0,03164 & 0,02880 & 0,01650 & 0,09310 & $-0,00620$ & 4028 \\
\hline IRate & 0,07785 & 0,07582 & 0,02972 & 0,14760 & 0,03511 & 4028 \\
\hline
\end{tabular}

Fonte dos dados: BCB e IBGE.

Notas: Para as estatísticas descritivas, o valor dos ativos não foi deflacionado. As variáveis estão todas em nível, exceto quando o contrário for expresso. Por exemplo, ROA de 0,03549 é lido como 3,549\% ou 3,55\%, arredondando.

Definição das variáveis: ROA: proxy de desempenho, representa o retorno sobre os ativos. ROE: proxy de desempenho, representa o retorno sobre o patrimônio líquido. Loans/Assets: empréstimos sobre os ativos, captando quanto o banco tem de operações de empréstimos em relação aos seus outros ativos bancários. ADC/Assets: provisão para operações de crédito sobre os ativos, captando a qualidade dos ativos. Debt/Assets: passivos exigíveis sobre ativos, captando o nível de endividamento do banco. DepTot: depósitos sobre outras formas de levar recursos, captando quanto dos depósitos representam no total de fontes de recursos do banco. Efficiency: custos operacionais sobre receitas, captando quão eficiente o banco é em obter mais receitas com menos custos. Size: tamanho do banco, sendo representado neste artigo por Assets (ativos totais). LogAssets (logaritmo dos ativos totais), Small (dummy que representa bancos pequenos), Medium (dummy que representa os bancos de tamanho mediano) e Large (dummy que representa os grandes bancos). Diversification: Índice Herfindahl-Hirschman $(I H H)$ calculado com a razão entre receitas específicas $\left(\operatorname{Rec}_{i}\right)$ e as receitas totais (Tot). Concentration: capta a concentração no mercado bancário por meio dos ativos $\left(I H H_{A s s e t s}\right)$, depósitos $\left(I H H_{D e p}\right)$ 
e operações de crédito $\left(I H H_{C r e d}\right)$; quando maior o índice, menor será a competição. EconGrowth: calculado pela variação real no PIB, captando ciclos econômicos de recessão (dummy Expansion) e expansão (dummy Recession). Inflation: IPCA. IRate: variação semestral da Selic.

As operações de crédito representaram, em média, 8,739\% dos ativos dos bancos no período estudado, o que pode indicar uma alta diversificação das atividades bancárias. Ao mesmo tempo, há instituições que detém mais da metade de suas aplicações representadas por operações de crédito. Na Espanha e EUA estes números apresentam significativa diferença, sendo esta mesma proporção, respectivamente, de 70,963\% e 61,060\%. A qualidade dos ativos também não aparenta ser preocupante para as instituições financeiras brasileiras. As perdas médias estimadas representam menos de $1 \%$ do valor dos ativos totais. A relação entre o passivo exigível e os ativos totais mostra semelhança com estudos anteriores, em que o capital próprio compreende, aproximadamente, 10\% dos ativos totais (Hoffmann, 2011; Rover et al., 2013; Trujillo-Ponce, 2013).

A proporção média de depósitos em relação ao passivo exigível chegou a quase $50 \%$, evidenciando que os bancos captam um percentual relevante de recursos de fontes consideradas mais baratas. Bancos espanhóis obtiveram ainda mais recursos $(74,154 \%)$ destas fontes mais econômicas (Trujillo-Ponce, 2013). Os bancos brasileiros apresentaram uma baixa eficiência no período estudado, com as despesas geradas correspondendo a grande parte das receitas auferidas. Em muitos casos, as despesas superaram as receitas, fazendo com que os bancos tivessem prejuízos. O tamanho médio dos bancos no período foi de aproximadamente $\mathrm{R} \$ 161$ bilhões, com as maiores instituições superando os $\mathrm{R} \$ 8$ trilhões em ativos e as menores apresentando aplicações de $\mathrm{R} \$ 13$ milhões.

A concentração de empresas em um mesmo setor é considerada alta quando o IHH apresenta valores acima de 0,18 e baixa para valores abaixo de 0,10 (Dantas et al., 2011; Trujillo-Ponce, 2013). Apesar de diversos meios de comunicação mostrarem o setor bancário como muito concentrado, as métricas aqui utilizadas não corroboram essas afirmações, todavia poucos bancos controlam a maior parte do mercado. O PIB durante o período cresceu em média 2,091\%, alternando momentos de boom (expansão) com alguns momentos de baixa econômica (recessão). A inflação máxima registrada nos períodos semestrais foi de $9,310 \%$. Por fim, a taxa de juros brasileira, considerada entre as maiores do mundo, apresentou média de 7,785\%, com apuração semestral, sendo considerada uma alta taxa de juros, dada a característica de países desenvolvidos em manter suas taxas de juros próximas a zero, ou até mesmo negativas em termos reais, mais recentemente.

\subsection{Estimadores, modelos e pressupostos econométricos}

Para atingir o objetivo desta pesquisa, trabalhamos com um modelo base, com variáveis já testadas com bancos brasileiros e estrangeiros, conforme a Equação 1.

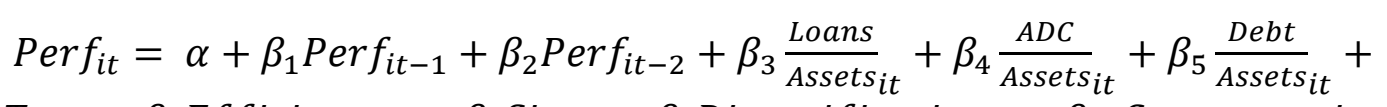

$\beta_{6}$ DebTot $_{i t}+\beta_{7}$ Efficiency $_{i t}+\beta_{8}$ Size $_{i t}+\beta_{9}$ Diversification $_{i t}+\beta_{10}$ Concentration $_{i t}+$ $\beta_{11}$ EconGrowth $_{i t}+\beta_{12}$ Inflation $_{i t}+\beta_{13}$ IRate $_{i t}+\varepsilon_{i t}$

Equação 1

Com as variáveis sendo definidas da seguinte maneira: Perf representa o desempenho do banco, medido pelo ROA ou ROE. ROA: proxy de desempenho, representa o retorno sobre os ativos. ROE: proxy de desempenho, representa o retorno sobre o patrimônio líquido. Loans/Assets: empréstimos sobre os ativos, captando quanto o banco tem de operações de empréstimos em relação aos seus outros ativos bancários. ADC/Assets: provisão para operações de crédito sobre os ativos, captando a qualidade dos ativos. Debt/Assets: passivos exigíveis sobre ativos, captando o nível de endividamento do banco. DepTot: depósitos sobre outras formas de levar recursos, captando quanto dos depósitos representam no total de fontes de recursos do banco. Efficiency: custos operacionais sobre receitas, captando quão eficiente o banco é em obter mais receitas com menos custos. Size: 
tamanho do banco, sendo representado neste artigo por Assets (ativos totais). LogAssets (logaritmo dos ativos totais), Small (dummy que representa bancos pequenos), Medium (dummy que representa os bancos de tamanho mediano) e Large (dummy que representa os grandes bancos). Diversification: Índice Herfindahl-Hirschman $(I H H)$ calculado com a razão entre receitas específicas $\left(R_{e c}\right)_{i}$ e as receitas totais (Tot). Concentration: capta a concentração no mercado bancário por meio dos ativos $\left(I H H_{\text {Assets }}\right)$, depósitos $\left(I H H_{D e p}\right)$ e operações de crédito $\left(I H H_{C r e d}\right)$; quando maior o índice, menor será a competição. EconGrowth: calculado pela variação real no PIB, captando ciclos econômicos de recessão (dummy Recession) e expansão (dummy Expansion). Inflation: IPCA. IRates: variação semestral da Selic.

Antes de realizar as estimações, nós testamos a presença de um alto grau de multicolinearidade entre as variáveis, por meio do VIF (Variance Inflation Factor). Nos modelos em que identificamos VIF acima de 10, a variável-problema foi removida.

Para a estimação dos modelos das Equações 1, 2 e 3, nós utilizamos o estimador de ArellanoBover/Blundell-Bond, conhecido como system-GMM, devido a possíveis problemas causados por simultaneidade, bem como para controlar a heterogeneidade não observada das características dos bancos.

Quando a amostra das regressões estimadas conta com um número reduzido de indivíduos, o estimador system-GMM de um estágio (one-step) pode se tornar assintoticamente ineficiente, enquanto o estimador em dois estágios (two-step) pode apresentar erros-padrão subestimados. Desta maneira, optamos por utilizar o estimador em dois estágios para estimar os modelos. Para lidar com uma eventual tendência deste estimador enviesar os erros-padrão, optamos por utilizar a correção de Windmeijer para amostras finitas.

\section{ANÁLISE DOS RESULTADOS}

\subsection{Resumo gráfico dos principais resultados da pesquisa}

Em suma, conforme a Figura 1, os nossos resultados evidenciaram que os fatores que tiveram mais peso no ROA médio dos bancos brasileiros, no período analisado, foram a dívida, a eficiência operacional, o tamanho do banco, a diversificação das receitas e a taxa de juros brasileira. Nem todos foram estatisticamente significativos e podemos perceber que a constante da regressão pode ter absorvido alguns fatores importantes que não foram segregados entre as variáveis utilizadas nesta pesquisa. Isso é importante para que pesquisas futuras busquem explorar outros fatores além daqueles já comuns nesta literatura e nesta pesquisa em específico, especialmente falando dos testes de sensibilidade realizados, explorados em detalhes na seção 4.3.

Pensando em significância estatística, nós podemos observar na Figura 2 que as variáveis que apresentaram significância de forma mais generalizada foram as provisões, a eficiência operacional, a diversificação das receitas e a concentração do mercado bancário, todas reduzindo a rentabilidade dos bancos brasileiros. Do lado positivo, tivemos a taxa de juros e o efeito da persistência da rentabilidade passada de um e dois períodos atrás. Os fatores positivos funcionam como uma defesa da rentabilidade, enquanto os fatores negativos tentam reduzir os fatores positivos. 


\section{Figura 1}

Peso dos Fatores que contribuíram para a Rentabilidade Média de 8,23\% dos Bancos Brasileiros

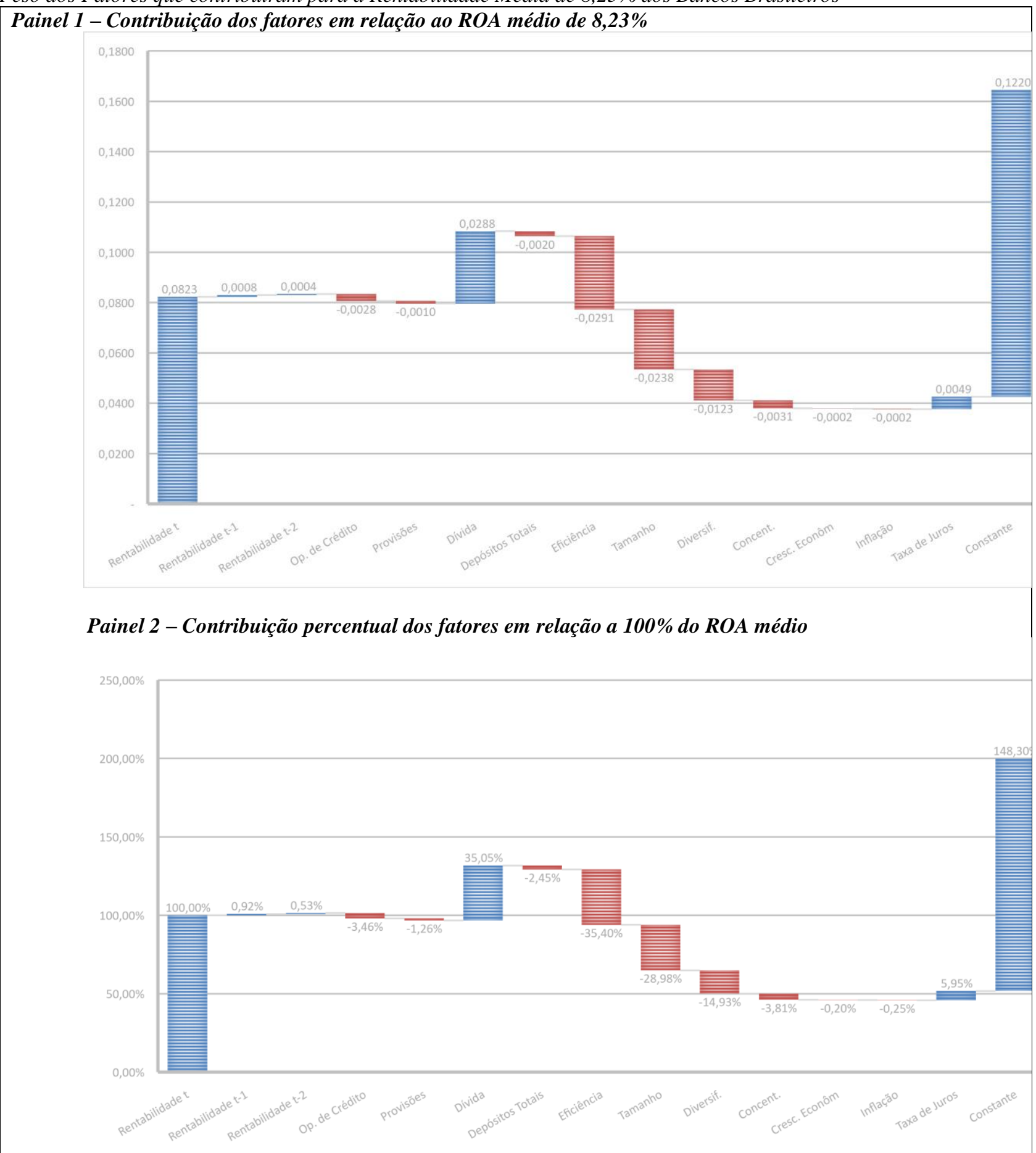

Fonte: Dados da Pesquisa. 
Figura 2

Fatores que Impactaram a Rentabilidade dos Bancos Brasileiros com Significância Estatística

Fatores que impactaram a rentabilidade dos bancos brasileiros (significativo estatisticamente)

Fatores que não impactaram a rentabilidade dos bancos brasileiros (sem significância estatística)

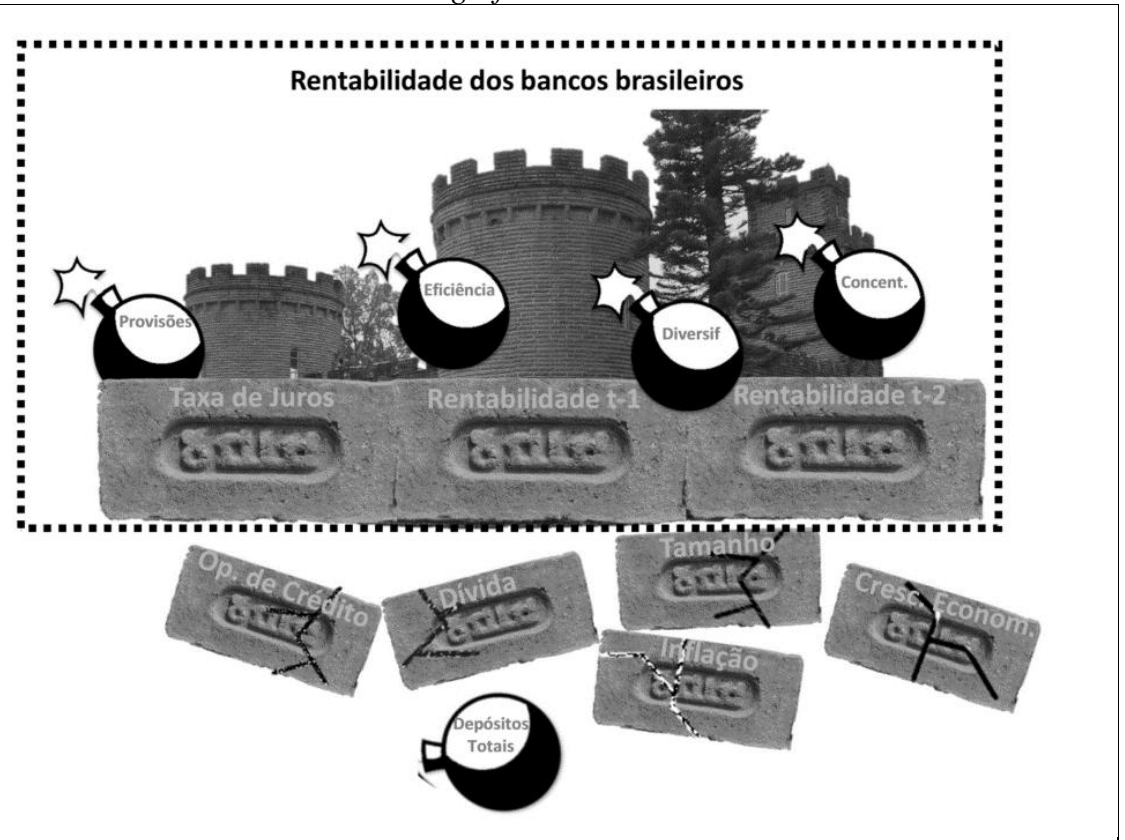

Fonte: Autores.

Nas próximas seções nós explicaremos em maiores detalhes os resultados dos modelos mais gerais e entraremos também em questões mais específicas por meio dos testes de sensibilidade.

Nós chamamos a atenção, especialmente, aos testes que foram realizados para identificar o efeito da concentração do mercado bancário na rentabilidade dos bancos. Dantas et al. (2011) acreditam que a concorrência pode ter impactado mais fortemente os bancos brasileiros após a Crise de 2008, porém, eles não tiveram amostra suficiente para testar isso com mais segurança. Desta forma, nós realizamos este teste de sensibilidade na seção 4.3.

Avaliamos ainda as seguintes questões adicionais nas próximas seções deste artigo:

- Os resultados da pesquisa se mantêm quando ajustamos os ROAs ao risco fundamentalista dos bancos?

- É possível ter alta rentabilidade com ativos de alta qualidade?

- A diversificação das receitas e a eficiência dos bancos protege a sua rentabilidade em ambientes mais competitivos?

\subsection{Análise dos fatores determinantes da rentabilidade bancária no Brasil}

Na Tabela 3 são apresentados os resultados das estimações para os modelos de 1 a 6 , baseados na Equação 1, que consideram o ROA como variável dependente. Não foi encontrada relação entre o percentual de recursos aplicados em operações de crédito $\left(\frac{\text { Loans }}{\text { Assets }}\right)$ e o ROA. Estes resultados são consistentes com os de García-Herrero et al. (2009), que não encontraram relação entre a proporção de operações de créditos em relação aos ativos totais e o ROA. 
Tabela 3

Determinantes da rentabilidade bancária $(R O A)$

\begin{tabular}{|c|c|c|c|c|c|c|c|}
\hline Variáveis & $\begin{array}{c}\text { Sinal } \\
\text { Esperado }\end{array}$ & & & Estimador & tem-GMM & & \\
\hline $\mathrm{ROA}_{\mathrm{it}-1}$ & + & $\begin{array}{l}\mathbf{0 , 1 9 8 7 *} \\
(0,1207)\end{array}$ & $\begin{array}{l}\mathbf{0 , 1 9 5 2} * \\
(0,1181)\end{array}$ & $\begin{array}{l}\mathbf{0 , 1 9 4 2} * \\
(0,1166)\end{array}$ & $\begin{array}{c}0,1894 \\
(0,1237)\end{array}$ & $\begin{array}{c}0,1863 \\
(0,1214)\end{array}$ & $\begin{array}{c}0,1856 \\
(0,1211)\end{array}$ \\
\hline $\mathrm{ROA}_{\mathrm{it}-2}$ & + & $\begin{array}{c}\mathbf{0 , 1 1 3 5} * * * * \\
(0,0251)\end{array}$ & $\begin{array}{c}\mathbf{0 , 1 1 0 8} * * * \\
(0,0251)\end{array}$ & $\begin{array}{c}\mathbf{0 , 1 0 9 6} * * * * \\
(0,0253)\end{array}$ & $\begin{array}{c}\mathbf{0 , 1 0 9 1} * * * \\
(0,0316)\end{array}$ & $\begin{array}{c}\mathbf{0 , 1 0 6 8} * * * * \\
(0,0283)\end{array}$ & $\begin{array}{c}\mathbf{0 , 1 0 6 3} * * * * \\
(0,0282)\end{array}$ \\
\hline$\frac{\text { Loan }}{\text { Assets }}$ it & + & $\begin{array}{l}-0,0326 \\
(0,0257)\end{array}$ & $\begin{array}{l}-0,0300 \\
(0,0243)\end{array}$ & $\begin{array}{l}-0,0298 \\
(0,0232)\end{array}$ & $\begin{array}{l}-0,0170 \\
(0,0192)\end{array}$ & $\begin{array}{l}-0,0147 \\
(0,0188)\end{array}$ & $\begin{array}{l}-0,0153 \\
(0,0191)\end{array}$ \\
\hline$\frac{\text { ADC }}{\text { Assets }}$ it & $+/-$ & $\begin{array}{c}-\mathbf{0 , 2 1 3 9} * * * \\
(0,0636)\end{array}$ & $\begin{array}{c}-\mathbf{0 , 2 1 6 6 * * *} \\
(0,0607)\end{array}$ & $\begin{array}{c}-\mathbf{0 , 2 1 6 2} * * * \\
(0,0593)\end{array}$ & $\begin{array}{c}-\mathbf{0 , 2 2 0 6} * * * * \\
(0,0656)\end{array}$ & $\begin{array}{r}-\mathbf{0 , 2 2 1 8} * * * * \\
(0,0657)\end{array}$ & $\begin{array}{c}-\mathbf{0 , 2 2 3 0} * * * * \\
(0,0649)\end{array}$ \\
\hline$\frac{\text { Debt }}{\text { Assets }}$ it & + & $\begin{array}{c}0,0316 \\
(0,0323)\end{array}$ & $\begin{array}{c}0,0301 \\
(0,0323)\end{array}$ & $\begin{array}{c}0,0291 \\
(0,0313)\end{array}$ & $\begin{array}{c}0,0092 \\
(0,0211)\end{array}$ & $\begin{array}{c}0,0084 \\
(0,0206)\end{array}$ & $\begin{array}{c}0,0081 \\
(0,0204)\end{array}$ \\
\hline DepTot $_{i t}$ & + & $\begin{array}{l}-0,0047 \\
(0,0112)\end{array}$ & $\begin{array}{l}-0,0046 \\
(0,0110)\end{array}$ & $\begin{array}{l}-0,0045 \\
(0,0113)\end{array}$ & $\begin{array}{l}-0,0045 \\
(0,0110)\end{array}$ & $\begin{array}{l}-0,0045 \\
(0,0111)\end{array}$ & $\begin{array}{l}-0,0046 \\
(0,0112)\end{array}$ \\
\hline Efficiencyit & - & $\begin{array}{c}-\mathbf{0 , 0 3 2 0} * * * * \\
(0,0095)\end{array}$ & $\begin{array}{c}-\mathbf{0 , 0 3 1 9} * * * * \\
(0,0093)\end{array}$ & $\begin{array}{c}-\mathbf{0 , 0 3 1 9} * * * * \\
(0,0093)\end{array}$ & $\begin{array}{c}-\mathbf{0 , 0 3 2 0} * * * * \\
(0,0090)\end{array}$ & $\begin{array}{c}-\mathbf{0 , 0 3 1 9 * * *} \\
(0,0089)\end{array}$ & $\begin{array}{c}-\mathbf{0 , 0 3 1 8} * * * * \\
(0,0089)\end{array}$ \\
\hline $\log _{\text {Assets }}$ it & + & $\begin{array}{l}-0,0108 \\
(0,0069)\end{array}$ & $\begin{array}{l}-0,0105 \\
(0,0067)\end{array}$ & $\begin{array}{l}-0,0104 \\
(0,0065)\end{array}$ & - & - & - \\
\hline Small $_{\text {it }}$ & - & - & - & - & $\begin{array}{l}-0,0024 \\
(0,0048)\end{array}$ & $\begin{array}{l}-0,0025 \\
(0,0050)\end{array}$ & $\begin{array}{l}-0,0026 \\
(0,0051)\end{array}$ \\
\hline Large $_{i t}$ & - & - & - & - & $\begin{array}{l}-0,0039 \\
(0,0034)\end{array}$ & $\begin{array}{l}-0,0037 \\
(0,0031)\end{array}$ & $\begin{array}{c}-0,0038 \\
(0,0032)\end{array}$ \\
\hline Diversification $_{\text {it }}$ & - & $\begin{array}{c}-\mathbf{0 , 0 2 2 5 *} \\
(0,0116)\end{array}$ & $\begin{array}{c}-\mathbf{0 , 0 2 2 0} * * \\
(0,0110)\end{array}$ & $\begin{array}{r}-\mathbf{0 , 0 2 2 3 *} \\
(0,0116)\end{array}$ & $\begin{array}{c}-\mathbf{0 , 0 2 3 7 * *} * \\
(0,0121)\end{array}$ & $\begin{array}{c}-\mathbf{0 , 0 2 3 5} * * \\
(0,0118)\end{array}$ & $\begin{array}{c}-\mathbf{- 0 , 0 2 3 8 *} \\
(0,0124)\end{array}$ \\
\hline IHHAssetsit & - & $\begin{array}{c}-\mathbf{0 , 0 2 8 2} * * \\
(0,0111)\end{array}$ & - & - & $\begin{array}{c}-\mathbf{0 , 0 1 8 2 *} \\
(0,0110)\end{array}$ & - & - \\
\hline IHHDep $_{\text {it }}$ & - & - & $\begin{array}{c}0,0308 \\
(0,0398)\end{array}$ & - & - & $\begin{array}{c}0,0491 \\
(0,0350)\end{array}$ & - \\
\hline IHHCred $_{\text {it }}$ & - & - & - & $\begin{array}{c}0,0560 \\
(0,0343)\end{array}$ & - & - & $\begin{array}{l}\mathbf{0 , 0 5 9 7 *} * \\
(0,0326)\end{array}$ \\
\hline EconGrowth $_{\text {it }}$ & + & $\begin{array}{l}-0,0080 \\
(0,0112)\end{array}$ & $\begin{array}{l}-0,0058 \\
(0,0110)\end{array}$ & $\begin{array}{l}-0,0071 \\
(0,0111)\end{array}$ & $\begin{array}{l}-0,0069 \\
(0,0105)\end{array}$ & $\begin{array}{l}-0,0047 \\
(0,0101)\end{array}$ & $\begin{array}{l}-0,0064 \\
(0,0107)\end{array}$ \\
\hline Inflation $_{\text {it }}$ & $+/-$ & $\begin{array}{l}-0,0065 \\
(0,0189)\end{array}$ & $\begin{array}{c}-0,0097 \\
(0,0181)\end{array}$ & $\begin{array}{l}-0,0127 \\
(0,0183)\end{array}$ & $\begin{array}{l}-0,0087 \\
(0,0207)\end{array}$ & $\begin{array}{l}-0,0095 \\
(0,0199)\end{array}$ & $\begin{array}{c}-0,0131 \\
(0,0211)\end{array}$ \\
\hline IRate $_{i t}$ & + & $\begin{array}{r}\mathbf{0 , 0 6 2 9} * * \\
(0,0279)\end{array}$ & $\begin{array}{c}\mathbf{0 , 0 7 0 7 * *} * \\
(0,0294)\end{array}$ & $\begin{array}{c}\mathbf{0 , 0 6 5 2 * *} \\
(0,0296)\end{array}$ & $\begin{array}{c}\mathbf{0 , 0 8 5 1} * * * * \\
(0,0304)\end{array}$ & $\begin{array}{c}\mathbf{0 , 0 8 9 0} * * * * \\
(0,0313)\end{array}$ & $\begin{array}{c}\mathbf{0 , 0 8 2 6} * * * * \\
(0,0307)\end{array}$ \\
\hline Constit & $?$ & $\begin{array}{c}\mathbf{0 , 1 2 2 0} * * * \\
(0,0531)\end{array}$ & $\begin{array}{c}\mathbf{0 , 1 1 3 4} * * \\
(0,0510)\end{array}$ & $\begin{array}{c}\mathbf{0 , 1 1 2 1} * * \\
(0,0487)\end{array}$ & $\begin{array}{c}\mathbf{0 , 0 3 8 4} * * * \\
(0,0132)\end{array}$ & $\begin{array}{c}\mathbf{0 , 0 3 2 2} * * \\
(0,0145)\end{array}$ & $\begin{array}{c}\mathbf{0 , 0 3 2 8} * * \\
(0,0140)\end{array}$ \\
\hline Wald $\chi^{2^{(a)}}$ & & $422,300 * * *$ & $393,26 * * *$ & $393,47 * * *$ & $457,54 * * *$ & $425,40 * * *$ & $471,54 * * *$ \\
\hline Maior VIF(b) & & 1,67 & 1,66 & 1,66 & 1,67 & 1,65 & 1,66 \\
\hline $\operatorname{AR}(1)^{(\mathrm{c})}$ & & $-3,557 * * *$ & $-3,5595 * * *$ & $-3,5584 * * *$ & $3,573 * * *$ & $-3,576^{* * *}$ & $-3,574 * * *$ \\
\hline $\operatorname{AR}(2)^{(c)}$ & & $-1,003$ & $-0,9952$ & $-0,9923$ & $-1,003$ & $-0,991$ & $-0,994$ \\
\hline Teste & & $99,23(104)$ & $100,43(104)$ & $101,95(104)$ & $100,94(104)$ & $99,01(104)$ & $101,39(104)$ \\
\hline Modelo & & $(1)$ & $(2)$ & (3) & (4) & $(5)$ & (6) \\
\hline
\end{tabular}

Fonte: Elaboração própria, com dados da pesquisa

Notas: Coeficientes em negrito, quando estatisticamente significativos, e erro-padrão entre parênteses e em itálico. Significância estatística: 1\%***, 5\%**, 10\%*; ( ${ }^{\text {a) }}$ Teste de Wald de significância geral do modelo de regressão; ${ }^{\left({ }^{b}\right)}$ Maior valor para o teste VIF; (c) Teste de correlação serial de ordem (n) usando resíduos de primeiras diferenças, sob a hipótese nula de ausência de correlação serial; ${ }^{(d)}$ Teste de Sargan de sobreidentificação de restrições.

Definição das variáveis: Perf = ROA: proxy de desempenho, representa o retorno sobre os ativos. Loans/Assets: empréstimos sobre os ativos, captando quanto o banco tem de operações de empréstimos em relação aos seus outros ativos bancários. ADC/Assets: provisão para operações de crédito sobre os ativos, captando a qualidade dos ativos. Debt/Assets: passivos exigíveis sobre ativos, captando o nível de endividamento do banco. DepTot: depósitos sobre outras formas de levar recursos, captando quanto dos depósitos representam no total de fontes de recursos do banco. Efficiency: custos operacionais sobre receitas, captando quão eficiente o banco é em obter mais receitas com menos custos. Size: tamanho do banco, sendo representado neste artigo por Assets (ativos totais). LogAssets (logaritmo dos ativos totais), Small (dummy que representa bancos pequenos), Medium (dummy que representa os bancos de tamanho mediano) e Large (dummy que representa os grandes bancos). Diversification: Índice Herfindahl-Hirschman $(I H H)$ calculado com a razão entre receitas específicas $\left(R e c_{i}\right)$ e as receitas totais (Tot). Concentration: capta a concentração no mercado bancário por meio dos ativos $\left(I H H_{\text {Assets }}\right)$, depósitos $\left(I H H_{D e p}\right)$ e operações de crédito $\left(I H H_{C r e d}\right)$; quando maior o índice, menor será a competição. 
EconGrowth: calculado pela variação real no PIB, captando ciclos econômicos de recessão (dummy Expansion) e expansão (dummy Recession). Inflation: IPCA. IRates: variação semestral da Selic.

Equação 1, base para os 6 modelos desta tabela: Perf $i t=\alpha+\beta_{1}$ Perf $_{i t-1}+\beta_{2}$ Perf $_{i t-2}+\beta_{3} \frac{\text { Loans }_{\text {Assets }} \text { it }}{}+\beta_{4} \frac{\text { ADC }}{\text { Assetsit }}+$ $\beta_{5} \frac{\text { Debt }_{\text {Assets }}}{\text { it }}+\beta_{6}$ DebTot $_{i t}+\beta_{7}$ Efficiency $_{i t}+\beta_{8}$ Size $_{i t}+\beta_{9}$ Diversification $_{i t}+\beta_{10}$ Concentration $_{i t}+$ $\beta_{11}$ EconGrowth $_{i t}+\beta_{12}$ Inflation $_{i t}+\beta_{13}$ IRate $_{i t}+\varepsilon_{i t}$

Por outro lado, podemos observar que a qualidade dos ativos $\left(\frac{A D C}{A s s e t s}\right)$, no caso da variável que representa a baixa qualidade, está negativamente relacionada com a rentabilidade medida pelo ROA. Isto ocorre porque a baixa qualidade dos ativos aumenta as perdas com inadimplência e, consequentemente, diminuem o resultado dos bancos, consistente com os resultados de TrujilloPonce (2013), Rover et al. (2013), Vinhado e Divino (2013) e Lee e Hsieh (2013). Se os bancos conseguissem fazer uma boa gestão do risco, poderiam se aproveitar melhor dos juros cobrados adicionalmente para compensar o risco assumido.

Diferentemente do previsto pela literatura, não foram encontradas relações estatisticamente significantes entre o endividamento $\left(\frac{D e b t}{\text { Assets }}\right)$ e o ROA. A maioria dos estudos catalogados está em desacordo com os achados desta pesquisa, em que um maior nível de endividamento está ligado a um menor ROA (Chen \& Liao, 2011; Tabak et al., 2011; Dietrich \& Wanzenried, 2011; Lee \& Hsieh, 2013; Mirzaei et al., 2013; Rover et al., 2013; Trujillo-Ponce, 2013; Vinhado \& Divino, 2013). Como esperado, a variável Efficiency está negativamente relacionada com a rentabilidade, o que indica que bancos mais eficientes são mais lucrativos. Esta relação persiste para todos os modelos analisados (Rover et al., 2013; Trujillo-Ponce, 2013).

Para nenhuma das especificações da variável Size foi encontrada uma relação estatisticamente significante com o ROA, indicando que bancos grandes e pequenos apresentam o mesmo nível médio de rentabilidade. Assim, não foi catalogada nenhuma relação logarítmica ou em forma de $\cap$ entre o tamanho e a rentabilidade. Estes resultados estão em linha com os encontrados por Trujillo-Ponce (2013) e Rover et al. (2013). Os achados da literatura financeira sobre estas relações são mistos, apresentando relações tanto positivas (Vinhado \& Divino, 2013) quanto negativas (Chen \& Liao, 2011; Mirzaei et al., 2013) entre o tamanho do banco e o ROA.

A variável Diversification apresentou sinal negativo e significância estatística em todos os modelos estimados. Os resultados indicam que a diversificação está negativamente relacionada com o ROA, o que pode indicar que os bancos diversificam suas atividades em setores nos quais não têm experiência e know-how suficientes, amargando baixos retornos ou até prejuízos. Adicionalmente, conforme a Moderna Teoria Financeira, não podemos esperar altos retornos com baixo nível de risco. Não foram encontrados resultados semelhantes em trabalhos anteriores que utilizaram esta mesma métrica para a diversificação das atividades (Trujillo-Ponce, 2013).

Dentre as variáveis econômicas consideradas no estudo, apenas IRate apresenta significância estatística confirmada na maioria dos modelos. O coeficiente positivo indica que quanto maiores forem as taxas de juros, mais rentáveis se tornam os bancos analisados. Este resultado indica que os bancos operantes no Brasil têm conseguido balancear os custos de captação e aplicação, de modo a obter um spread que garanta a sua rentabilidade. Esta hipótese também é confirmada nos trabalhos de Rover et al., (2013), Lee e Hsieh (2013), Vinhado e Divino (2013), Primo et al. (2013) e Chen e Liao (2011). Trujillo-Ponce (2013) e Dietrich e Wanzenried (2011) encontraram uma relação negativa entre a taxa de juros e o ROA.

Na Tabela 4 observamos os resultados das estimações para os modelos de 7 a 12, baseados na Equação 1, que utilizam o ROE como variável dependente. Assim como nos resultados obtidos para o ROA, não foi encontrada associação entre o nível de ativos alocados para operações de crédito $\left(\frac{\text { Loans }}{\text { Assets }}\right)$ o ROE. Estes resultados corroboram os resultados obtidos na Tabela 3, em que a proporção de investimentos em operações de crédito não influenciou o desempenho dos bancos operantes no 
Brasil no período estudado. Enquanto Trujillo-Ponce (2013) e Hoffmann (2011) encontraram uma associação positiva entre esta variável e o ROE, Lee e Hsieh (2013) descobriram que quanto maior a ênfase em operações de crédito, menor foi a rentabilidade dos bancos.

Apesar da relação negativa da qualidade dos ativos $\left(\frac{A D C}{A s s e t s}\right)$ com o ROA, ela não impacta a rentabilidade na ótica dos investidores (ROE), consistente com os estudos de Dietrich e Wanzenried (2011). Estes resultados são divergentes dos encontrados por Trujillo-Ponce (2013), Vinhado e Divino (2013) e Lee e Hsieh (2013), que descobriram uma relação negativa entre o ROE e esta variável.

\section{Tabela 4}

Determinantes da rentabilidade bancária $(R O E)$

\begin{tabular}{|c|c|c|c|c|c|c|c|}
\hline Variáveis & $\begin{array}{c}\text { Sinal } \\
\text { Esperado }\end{array}$ & & & Estimado & em-GMM & & \\
\hline $\mathrm{ROE}_{\mathrm{it}-1}$ & + & $\begin{array}{c}\mathbf{0 , 0 5 6 3} * * \\
(0,0226)\end{array}$ & $\begin{array}{c}\mathbf{0 , 0 5 4 8} * * * * \\
(0,0202)\end{array}$ & $\begin{array}{c}\mathbf{0 , 0 5 5 3} * * * \\
(0,0201)\end{array}$ & $\begin{array}{c}\mathbf{0 , 0 5 7 5} * * * \\
(0,0202)\end{array}$ & $\begin{array}{c}\mathbf{0 , 0 5 4 9} * * * * \\
(0,0200)\end{array}$ & $\begin{array}{c}\mathbf{0 , 0 5 6 6} * * * * \\
(0,0192)\end{array}$ \\
\hline $\mathrm{ROE}_{\mathrm{it}-2}$ & + & $\begin{array}{l}-0,0391 \\
(0,0405)\end{array}$ & $\begin{array}{l}-0,0379 \\
(0,0408)\end{array}$ & $\begin{array}{l}-0,0373 \\
(0,0388)\end{array}$ & $\begin{array}{l}-0,0383 \\
(0,0412)\end{array}$ & $\begin{array}{c}-0,0383 \\
(0,0409)\end{array}$ & $\begin{array}{l}-0,0386 \\
(0,0400)\end{array}$ \\
\hline$\frac{\text { Loan }}{\text { Assets }}$ it & + & $\begin{array}{c}0,0201 \\
(0,1882)\end{array}$ & $\begin{array}{l}-0,0001 \\
(0,1779)\end{array}$ & $\begin{array}{l}-0,0308 \\
(0,1834)\end{array}$ & $\begin{array}{c}0,0117 \\
(0,1370)\end{array}$ & $\begin{array}{l}-0,0182 \\
(0,1327)\end{array}$ & $\begin{array}{l}-0,0463 \\
(0,1332)\end{array}$ \\
\hline$\frac{\text { ADC }}{\text { Assets }}$ it & $+/-$ & $\begin{array}{l}-0,3191 \\
(0,2898)\end{array}$ & $\begin{array}{l}-0,3218 \\
(0,3492)\end{array}$ & $\begin{array}{l}-0,3492 \\
(0,3965)\end{array}$ & $\begin{array}{l}-0,2471 \\
(0,3435)\end{array}$ & $\begin{array}{l}-0,3700 \\
(0,3346)\end{array}$ & $\begin{array}{l}-0,3909 \\
(0,3144)\end{array}$ \\
\hline$\frac{\text { Debt }}{\text { Assets }}$ it & + & $\begin{array}{c}0,1091 \\
(0,2758)\end{array}$ & $\begin{array}{c}0,1194 \\
(0.2673)\end{array}$ & $\begin{array}{c}0,1292 \\
(0,2597)\end{array}$ & $\begin{array}{c}0,1500 \\
(0,1411)\end{array}$ & 0,1258 & 0,1176 \\
\hline DepTot $_{\text {it }}$ & + & $\begin{array}{c}-0,0339 \\
(0,0552)\end{array}$ & $\begin{array}{c}-0,0348 \\
(0,0636)\end{array}$ & $\begin{array}{l}-0,0343 \\
(0,0637)\end{array}$ & $\begin{array}{l}-0,0361 \\
(0,0612)\end{array}$ & $\begin{array}{l}-0,0375 \\
(0,0620)\end{array}$ & $\begin{array}{r}-0,0339 \\
(0,0582)\end{array}$ \\
\hline Efficiencyit & - & $\begin{array}{c}-\mathbf{0 , 2 6 2 2} * * \\
(0,1281)\end{array}$ & $\begin{array}{c}-\mathbf{0 , 2 6 4 4} * * \\
(0,1262)\end{array}$ & $\begin{array}{c}-\mathbf{0 , 2 6 2 9} * * \\
(0,1253)\end{array}$ & $\begin{array}{c}-\mathbf{0 , 2 5 9 1} * * \\
(0,1258)\end{array}$ & $\begin{array}{c}-\mathbf{0 , 2 6 0 0} * * \\
(0,1279)\end{array}$ & $\begin{array}{c}-\mathbf{0 , 2 6 2 3} * * \\
(0,1206)\end{array}$ \\
\hline LogAssetsit & + & $\begin{array}{c}0,0131 \\
(0,0519)\end{array}$ & $\begin{array}{c}0,0153 \\
(0,0464)\end{array}$ & $\begin{array}{c}0,0082 \\
(0,0457)\end{array}$ & - & - & - \\
\hline Small $_{\text {it }}$ & - & - & - & - & $\begin{array}{l}-0,0122 \\
(0,0299)\end{array}$ & $\begin{array}{l}-0,0209 \\
(0,0311)\end{array}$ & $\begin{array}{l}-0,0163 \\
(0,0322)\end{array}$ \\
\hline Large $_{i t}$ & - & - & - & - & $\begin{array}{c}0,0106 \\
(0,0290)\end{array}$ & $\begin{array}{c}0,0177 \\
(0,0334)\end{array}$ & $\begin{array}{c}0,0139 \\
(0,0286)\end{array}$ \\
\hline Diversification $_{\text {it }}$ & - & $\begin{array}{l}-0,0646 \\
(0,0768)\end{array}$ & $\begin{array}{l}-0,0787 \\
(0,0768)\end{array}$ & $\begin{array}{l}-0,0864 \\
(0,0733)\end{array}$ & $\begin{array}{l}-0,0694 \\
(0,0748)\end{array}$ & $\begin{array}{l}-0,0763 \\
(0,0762)\end{array}$ & $\begin{array}{l}-0,0793 \\
(0,0668)\end{array}$ \\
\hline IHHAssetsit & - & $\begin{array}{c}\mathbf{0 , 2 7 4 5} * * \\
(0,1385)\end{array}$ & - & - & $\begin{array}{c}\mathbf{0 , 2 6 9 6} * * \\
(0,1237)\end{array}$ & - & - \\
\hline IHHDepit $_{\text {it }}$ & - & - & $\begin{array}{c}\mathbf{1 , 5 2 2 0} * * * * \\
(0,4132)\end{array}$ & - & - & $\begin{array}{c}\mathbf{1 , 4 5 9 5 * * * *} \\
(0,4143)\end{array}$ & - \\
\hline IHHCred $_{\text {it }}$ & - & - & - & $\begin{array}{c}\mathbf{1 , 5 3 7 8} * * * \\
(0,5756)\end{array}$ & - & - & $\begin{array}{c}\mathbf{1 , 5 0 2 9} * * * \\
(0,3992)\end{array}$ \\
\hline EconGrowth $_{\text {it }}$ & + & $\begin{array}{c}\mathbf{0 , 1 6 2 1} * * \\
(0,0762)\end{array}$ & $\begin{array}{c}\mathbf{0 , 1 8 0 0} * * \\
(0,0802)\end{array}$ & $\begin{array}{l}\mathbf{0 , 1 4 9 4} * \\
(0,0804)\end{array}$ & $\begin{array}{c}\mathbf{0 , 1 5 5 6} * * \\
(0,0740)\end{array}$ & $\begin{array}{c}\mathbf{0 , 1 7 6 0} * * \\
(0,0809)\end{array}$ & $\begin{array}{c}\mathbf{0 , 1 5 3 7} * * \\
(0,0751)\end{array}$ \\
\hline Inflation $_{\text {it }}$ & $+/-$ & $\begin{array}{c}\mathbf{0 , 5 9 7 8} * * \\
(0,2763)\end{array}$ & $\begin{array}{c}\mathbf{0 , 6 7 6 8} * * \\
(0,2858)\end{array}$ & $\begin{array}{c}\mathbf{0 , 6 3 2 1} * * \\
(0,2690)\end{array}$ & $\begin{array}{c}\mathbf{0 , 5 8 8 5} * * \\
(0,2647)\end{array}$ & $\begin{array}{c}\mathbf{0 , 6 6 6 6 * *} * \\
(0,2805)\end{array}$ & $\begin{array}{c}\mathbf{0 , 6 0 4 9} * * \\
(0,2580)\end{array}$ \\
\hline IRate $_{i t}$ & + & $\begin{array}{c}\mathbf{1 , 2 0 0 7} * * * \\
(0,4367)\end{array}$ & $\begin{array}{c}\mathbf{1 , 1 8 4 5} * * \\
(0,4932)\end{array}$ & $\begin{array}{l}\mathbf{0 , 9 3 6 9 *} \\
(0,5076)\end{array}$ & $\begin{array}{c}\mathbf{1 , 1 4 0 4} * * \\
(0,4756)\end{array}$ & $\begin{array}{c}\mathbf{1 , 1 5 6 9} * * \\
(0,4546)\end{array}$ & $\begin{array}{l}\mathbf{0 , 9 2 3 5}^{*} \\
(0,4728)\end{array}$ \\
\hline Const $_{\text {it }}$ & ? & $\begin{array}{l}-0,0179 \\
(0,3708)\end{array}$ & $\begin{array}{l}-0,1375 \\
(0,3733)\end{array}$ & $\begin{array}{l}-0,0477 \\
(0,3427)\end{array}$ & $\begin{array}{c}0,0741 \\
(0,1602)\end{array}$ & $\begin{array}{c}0,0041 \\
(0,2213)\end{array}$ & $\begin{array}{c}0,0394 \\
(0,1563)\end{array}$ \\
\hline Wald $\chi^{2 \text { (a) }}$ & & $155,07 * * *$ & $207,38 * * *$ & $224,45 * * *$ & $149,56^{* * *}$ & $206,31 * * *$ & $444,38 * * *$ \\
\hline Maior VIF (b) & & 1,74 & 1,74 & 1,74 & 1,73 & 1,71 & 1,72 \\
\hline $\operatorname{AR}(1)^{(c)}$ & & $-3,434 * * *$ & $-3,438 * * *$ & $-3,434 * * *$ & $-3,436^{* * *}$ & $-3,437 * * *$ & $-3,428 * * *$ \\
\hline $\operatorname{AR}(2)^{(c)}$ & & 0,150 & 0,128 & 0,104 & 0,147 & 0,152 & 0,143 \\
\hline Sargan test $(\mathrm{d})$ & & $89,00(104)$ & $91,56(104)$ & $90,93(104)$ & $86,89(104)$ & $90,31(104)$ & $87,94(104)$ \\
\hline Modelo & & (7) & (8) & (9) & (10) & (11) & (12) \\
\hline
\end{tabular}

Fonte: Elaboração própria, com dados da pesquisa

Notas: Coeficientes em negrito, quando estatisticamente significativos, e erro-padrão entre parênteses e em itálico. Significância estatística: $1 \% * * *, 5 \% * *, 10 \% *$; ${ }^{(a)}$ Teste de Wald de significância geral do modelo de regressão; ${ }^{\left({ }^{b}\right)}$ Maior valor para o teste VIF; (c) Teste de correlação serial de ordem (n) usando resíduos de primeiras diferenças, sob a hipótese nula de ausência de correlação serial; ${ }^{(d)}$ Teste de Sargan de sobreidentificação de restrições. 
Definição das variáveis: Perf = ROE: proxy de desempenho, representa o retorno sobre o patrimônio líquido. Loans/Assets: empréstimos sobre os ativos, captando quanto o banco tem de operações de empréstimos em relação aos seus outros ativos bancários. ADC/Assets: provisão para operações de crédito sobre os ativos, captando a qualidade dos ativos. Debt/Assets: passivos exigíveis sobre ativos, captando o nível de endividamento do banco. DepTot: depósitos sobre outras formas de levar recursos, captando quanto dos depósitos representam no total de fontes de recursos do banco. Efficiency: custos operacionais sobre receitas, captando quão eficiente o banco é em obter mais receitas com menos custos. Size: tamanho do banco, sendo representado neste artigo por Assets (ativos totais). LogAssets (logaritmo dos ativos totais), Small (dummy que representa bancos pequenos), Medium (dummy que representa os bancos de tamanho mediano) e Large (dummy que representa os grandes bancos). Diversification: Índice Herfindahl-Hirschman (IHH) calculado com a razão entre receitas específicas $\left(R e c_{i}\right)$ e as receitas totais $(T o t)$. Concentration: capta a concentração no mercado bancário por meio dos ativos $\left(I H H_{\text {Assets }}\right)$, depósitos $\left(I H H_{\text {Dep }}\right)$ e operações de crédito $\left(I H H_{C r e d}\right)$; quando maior o índice, menor será a competição. EconGrowth: calculado pela variação real no PIB, captando ciclos econômicos de recessão (dummy Expansion) e expansão (dummy Recession). Inflation: IPCA. IRates: variação semestral da Selic.

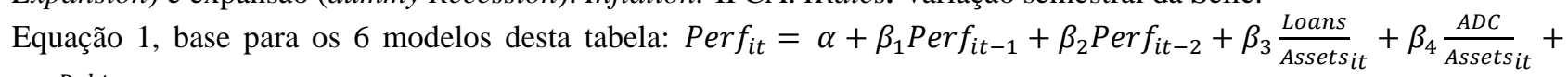
$\beta_{5} \frac{\text { Debt }_{\text {Assets }} i t}{\beta_{1}}+\beta_{6}$ DebTot $_{i t}+\beta_{7}$ Efficiency $_{i t}+\beta_{8}$ Size $_{i t}+\beta_{9}$ Diversification $_{i t}+\beta_{10}$ Concentration $_{i t}+$ $\beta_{11}$ EconGrowth $_{i t}+\beta_{12}$ Inflation $_{i t}+\beta_{13}$ IRate $_{i t}+\varepsilon_{i t}$

Novamente, não foi encontrada uma relação significante entre o nível de endividamento $\left(\frac{\text { Debt }}{\text { Assets }}\right)$ e o ROE, resultado similar àqueles obtidos no estudo de Dietrich e Wanzenried (2011). Ao contrário da relação esperada entre o endividamento e o ROA, a maioria das pesquisas analisadas apresenta uma relação positiva entre o endividamento e o ROE (Tabak et al., 2011; Chen \& Liao, 2011; Lee \& Hsieh, 2013; Trujillo-Ponce, 2013), com exceção do trabalho de Vinhado e Divino (2013). Em linha com os resultados obtidos na Tabela 3, a variável Efficiency mostrou coeficiente negativo e estatisticamente significante em todos os modelos estimados, indicando que quanto maior a proporção de custos em relação às receitas auferidas pelos bancos, menor a sua rentabilidade.

A variável Size não apresentou significância estatística em nenhuma das configurações de proxies, no que tange à explicação dos ROEs dos bancos brasileiros. Pudemos constatar, ainda, que o porte dos bancos não influencia os seus ROEs, assim como em Trujillo-Ponce (2013). Na literatura financeira, resultados mistos foram observados entre o ROE e o tamanho dos bancos, em que associações positivas (Chen \& Liao, 2011; Tabak et al., 2011) e negativas (Hoffmann, 2011; Mirzaei et al., 2013) foram encontradas. De acordo com os modelos estimados na Tabela 4, Diversification não influencia a rentabilidade, quando medida pelo ROE.

A maioria das variáveis macroeconômicas apresentou significância estatística nos modelos da Tabela 4. A concentração do setor (IHH em suas três variações) apresentou um coeficiente positivo e estatisticamente significante para todas as proxies utilizadas. Isso indica que quanto mais concentrado for o ambiente econômico das instituições financeiras, menor foi o retorno obtido. A concorrência se mostra então como um fator de alto impacto negativo na rentabilidade dos bancos (Hannan \& Prager, 2009). EconGrowth e IRate impactaram positivamente o retorno obtido pelos bancos. A maioria dos trabalhos analisados é quase unânime em reconhecer a relação positiva entre o crescimento econômico e a rentabilidade, quando medida pelo ROE (Chen \& Liao, 2011; Lee \& Hsieh, 2013; Mirzaei et al., 2013; Trujillo-Ponce, 2013; Primo et al. 2013).

Com relação à taxa de juros, os trabalhos anteriores indicam que sua influência no ROE pode ser positiva (Chen \& Liao, 2011; Vinhado \& Divino, 2013; Primo et al. 2013) ou negativa (Dietrich \& Wanzenried, 2011; Lee \& Hsieh, 2013; Trujillo-Ponce, 2013), estando o efeito desta variável ligado à capacidade do banco em manter seu spread em níveis altos. O resultado para a variável Inflation implica que as instituições conseguiram prever os efeitos adversos desse fenômeno e estruturar seu portfólio de aplicações, a fim de não serem prejudicados pela mudança no nível de preços da economia (Rover et al., 2013; Trujillo-Ponce, 2013; Primo et al. 2013). 


\subsection{Testes de sensibilidade}

Nesta seção apresentamos apenas a análise dos resultados, sem tabulá-los. Contudo, as tabelas poderão ser enviadas aos interessados, caso solicitem por e-mail aos autores.

\subsubsection{Efeito da concentração do mercado na rentabilidade dos bancos}

Dantas et al. (2011) apresentaram evidências de que a concentração no mercado bancário começou a crescer a partir de 2008, assim como Vinhedo e Divino (2013). Todavia, consideramos que não houve tempo suficiente para avaliar o impacto da Crise de 2008 no efeito conjunto com a concentração do mercado na rentabilidade dos bancos brasileiros.

Para avaliar o efeito conjunto do pós-Crise de 2008 e a concentração do mercado na rentabilidade bancária, realizamos o teste inserindo uma variável dummy para representar o período pós-Crise de 2008 e interagimos esta dummy com as proxies de concentração. Ou seja, adaptamos os Modelos 1, 2 e 3, disponíveis na Tabela 3.

Nossos resultados apontaram que o efeito da concentração medida pelo $\mathrm{IHH}_{\text {Assets }}$ passou a impactar mais negativamente a rentabilidade dos bancos brasileiros, no pós-Crise de 2008. O efeito da variável $\mathrm{IHH}_{\text {Assets }}$ cresceu $283 \%$ em relação à estimativa da Tabela 3, sendo significativo ao nível de $1 \%$, contra $5 \%$ anteriores. Não foram identificadas alterações significativas nas outras duas proxies para concentração ( $\mathrm{IHH}_{\text {Dep }}$ e IHHCred).

\subsubsection{Os determinantes do ROA ajustado ao risco são os mesmos do ROA bruto?}

Para ajustar o ROA ao risco, nós criamos uma variável dependente de rentabilidade ajustada ao risco por meio da razão entre o ROA e a sua volatilidade medida pelo desvio-padrão dos ROAs dos últimos 3 anos. Esta é uma métrica semelhante ao já muito conhecido Índice de Sharpe para a avaliação de retornos dos investimentos ajustados ao risco.

No geral, os resultados se mantiveram qualitativamente semelhantes, alterando apenas as seguintes variáveis determinantes da rentabilidade dos bancos brasileiros:

- Loans/Assets: passou a ter impacto positivo e significativo ao nível de 5\%, conforme esperado teoricamente; e

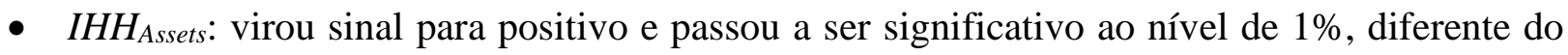
que era esperado teoricamente.

\subsubsection{Detalhamento da análise risco $x$ retorno nos bancos brasileiros: é possível ter alta rentabilidade com ativos de alta qualidade?}

Conforme a Moderna Teoria Financeira, a assunção de maior risco gera uma expectativa de retornos maiores. Os nossos resultados apresentados na Tabela 3 indicaram que quanto mais alta for a qualidade dos ativos do banco, menor seriam os ROAs futuros. Há explicação teórica para o sinal positivo e para o sinal negativo. Contudo, nós acreditamos que de fato ativos de qualidade mais baixa geram juros maiores para os bancos, porém, o risco precisa ser muito bem controlado para que o retorno esperado se torne retorno realizado.

Para testar esta hipótese, nós criamos uma variável dummy para indicar os bancos que não conseguem controlar bem o seu risco: HighVol, que assumiu valor 1 quando o desvio-padrão dos ROAs dos últimos 3 anos estava entre os $25 \%$ maiores da amostra. Após a criação da dummy, efetuamos a interação entre ela e a proxy para qualidade dos ativos (ADC/Assets).

Com a inclusão da variável HighVol e a sua interação com ADC/Assets no Modelo 1, nós identificamos que, individualmente, ADC/Assets perdeu a sua significância estatística, apesar de manter o sinal negativo. A interação entre HighVol e ADC/Assets, apesar de apresentar sinal positivo, não foi estatisticamente significativa. 
Por outro lado, apesar de o controle de risco não parecer ajudar na manutenção ou aumento da rentabilidade dos bancos brasileiros em geral, em períodos de recessão, a qualidade dos ativos melhora a sua rentabilidade, ao nível de significância de $5 \%$.

\subsubsection{A diversificação das receitas dos bancos protege a rentabilidade em ambientes mais competitivos?}

Também conforme a Moderna Teoria Financeira, esperava-se que a diversificação de receitas reduzisse a rentabilidade dos bancos brasileiros, e foi isso que observamos conforme na Tabela 3 . Todavia, em ambientes mais competitivos, ou menos concentrados, a diversificação das receitas pode ser uma boa forma de proteger a rentabilidade dos bancos, como se fosse um hedge. Desta forma, testamos se em ambientes mais competitivos, a diversificação das receitas protege a rentabilidade dos bancos.

Para isso, nós criamos uma dummy (HighCompetition) que assume valor 1 para cada período em que o nível de concentração estava alto - $25 \%$ dos períodos com menor competição e maior concentração. Após isso, interagimos HighCompetition com a variável Diversification.

Nossos resultados apontaram que a diversificação das receitas, em um ambiente de alta concentração do mercado bancário em ativos $\left(I H H_{\text {Assets }}\right)$, não protegeu a rentabilidade dos bancos brasileiros $(p$-value $=0,971)$. Por outro lado, em períodos de maiores concentrações em termos de depósitos $\left(I H H_{D e p}\right)$ e crédito $\left(I H H_{C r e d}\right)$, a rentabilidade dos bancos tende a ser menor, dummies com sinais negativos e significantes ao nível de 5\%. Adicionalmente, bancos com receitas mais diversificadas têm rentabilidades maiores em ambientes de maior competição em termos de depósitos e crédito, ao nível de $5 \%$ e $1 \%$, respectivamente.

Adicionalmente, nós testamos se estes resultados podem variar de acordo com o tamanho do banco. Para tanto, no lugar de utilizar as dummies Small e Large, que representam os $25 \%$ menores e os $25 \%$ maiores bancos, utilizamos a dummy Middle, para captar o efeito dos bancos médios e gerar um modelo mais parcimonioso, dado o número de variáveis inseridas, com uma interpretação, inclusive, mais fácil.

Quando a competição no mercado bancário foi estimada por meio dos ativos $\left(I H H_{\text {Assets }}\right)$, a diversificação de receitas dos bancos médios em ambientes mais competitivos parece não fazer nenhum efeito na rentabilidade. Por outro lado, quando a competição foi mensurada com base nos depósitos $\left(I H_{D e p}\right)$ e no crédito $\left(I H_{C r e d}\right)$, há o mesmo impacto negativo, ao nível de $10 \%$, que foi encontrado na Tabela 3 sem a interação com o tamanho do banco.

\subsubsection{A eficiência dos bancos protege a rentabilidade em ambientes mais competitivos?}

Seguindo o mesmo raciocínio da seção anterior, realizamos o teste de proteção da receita em ambientes mais competitivos com base na eficiência dos bancos. Na Tabela 3 nós percebemos que a eficiência tem impacto negativo e significativo na rentabilidade dos bancos brasileiros, conforme esperado.

Neste novo teste do efeito da eficiência dos bancos na sua rentabilidade, nós identificamos que a eficiência, individualmente, continua impactando negativamente a rentabilidade, conforme esperado, e que mesmo em ambientes altamente competitivos, a eficiência tende a continuar afetando negativamente os retornos. Ou seja, a eficiência é de fato um hedge geral que tem o custo de reduzir a rentabilidade do banco em ambientes diversos.

Adicionalmente, como fizemos na seção anterior, nós testamos se estes resultados podem variar de acordo com o tamanho do banco. Em ambientes de alta competição, os bancos médios têm rentabilidades maiores - com a competição sendo medida pelos ativos $\left(I H H_{\text {Assets }}\right)$ e pelos depósitos $\left(I H H_{D e p}\right)$, com significância estatística de $5 \%$ e $10 \%$, respectivamente. Com relação ao crédito $\left(I H H_{C r e d}\right)$ não houve significância estatística $(p$-value $=0,118)$, apesar do coeficiente positivo. Este resultado é diferente daquele encontrado na seção anterior, dado que a diversificação de receitas não 
tem efeito diferente para os bancos médios, mas aqui, com relação à eficiência, os bancos médios se beneficiam em ambientes de maior competição.

\section{CONSIDERAÇÕES FINAIS}

O estudo da rentabilidade no setor financeiro é de extrema importância para investidores, gestores e legisladores, uma vez que choques econômicos nesta área afetam de sobremaneira a economia de um país. A recente crise financeira de 2008, a crise da dívida grega e dos bancos escandinavos ilustram bem a importância deste tema na atualidade. O Brasil apresenta, até então, poucas pesquisas nesta área. Este trabalho busca contribuir para a literatura nacional e internacional acerca do tema, principalmente pela utilização de métodos mais robustos de estimação (systemGMM), sendo que quase não se documentou seu uso em trabalhos desta natureza na literatura nacional até aqui.

Primeiramente, observamos através das estimações que utilizaram o ROA como variável dependente que, dentre as variáveis específicas dos bancos, a qualidade dos ativos, a eficiência operacional e a diversificação das atividades influenciam o desempenho dos bancos operantes no Brasil. De acordo com os resultados encontrados, ao concederem créditos a clientes com menor probabilidade de pagamento, apesar de teoricamente cobrarem juros mais altos, os prejuízos originários dessas operações estão afetando negativamente seus resultados. Como esperado, bancos com menor proporção de custos em relação às receitas (mais eficientes) apresentaram maior rentabilidade quando comparados aos demais. Já a relação negativa entre a diversificação e o ROA sugere que os bancos não estão conseguindo auferir os benefícios da diversificação em seus resultados. Outra interpretação para esta relação é que os bancos diversificam suas atividades para diminuir seu risco e não para aumentar sua rentabilidade. Porém, Vieira e Girão (2016) não encontraram relação entre a diversificação das atividades e o risco dos bancos operantes no Brasil. Neste caso, a diversificação poderia ser estudada em relação ao problema de agência.

Ao se analisar o ROE como proxy para a rentabilidade bancária, os resultados obtidos para as variáveis a nível específico foram divergentes, uma vez que nem a qualidade dos ativos nem a diversificação mostrou-se estatisticamente significante nos modelos estimados. Novamente, observou-se que bancos mais eficientes apresentaram maior rentabilidade, assim como esperado por Trujillo-Ponce (2013) e Rover et al. (2013). Ao analisarmos as variáveis macroeconômicas, pudemos observar que elas têm um efeito distinto, dependendo de qual foi a proxy utilizada para se representar a rentabilidade. Enquanto as taxas de juros apresentaram influência positiva sobre a rentabilidade medida tanto pelo ROA quanto pelo ROE, a concentração, o crescimento econômico e a inflação se mostraram relevantes apenas nas estimações que consideravam o ROE como variável dependente. Estes resultados indicam que fatores macroeconômicos têm pouca influência no desempenho geral do banco, mas influenciam fortemente a riqueza dos seus proprietários.

A concorrência influenciou fortemente a rentabilidade dos bancos, sendo medida com relação aos ativos, operações de crédito ou depósitos. Isso corrobora a hipótese de que os resultados dos bancos são inferiores quando o setor no qual atuam é altamente concentrado. Ainda assim, pelas estatísticas descritas na Tabela 2, em nenhuma métrica o setor financeiro brasileiro foi considerado altamente competitivo, de acordo com os estudos analisados (Dantas et al., 2011; Trujillo-Ponce, 2013).

Algumas das principais variáveis estudadas na literatura financeira não apresentaram significância estatística nos modelos estimados. Essas variáveis são o tamanho e o nível de endividamento. Hipóteses concorrentes corroboram o fato de que bancos maiores podem se aproveitar de seu porte e influências políticas para realizar operações de crédito maiores e mais lucrativas, o que justificaria uma relação positiva entre o tamanho e a rentabilidade. Tanto para o tamanho medido pelo logaritmo dos ativos quanto para a variável dummy que representava os bancos grandes, não foi 
observada influência na rentabilidade. Ao mesmo tempo, a hipótese de que a relação entre o tamanho e a rentabilidade bancária se dava em forma de $\cap$ também foi rejeitada.

Esta pesquisa contribui para a literatura específica sobre a rentabilidade bancária, sobretudo em países emergentes, ao utilizar um método robusto para estimação dos parâmetros dos modelos de regressão (system-GMM), que torna os estimadores menos sensíveis a vieses oriundos da endogeneidade presente entre as variáveis. O trabalho ainda utilizou um período mais extenso (1996 a 2015) que outras pesquisas realizadas no Brasil, como Dantas et al. (2011) [2000 a 2009], Primo et al. (2013) [2000 a 2009], Rover et al. (2013) [1995 a 2009] e Vinhado e Divino (2013) [2000 a 2008]. Para pesquisas futuras, aconselhamos a análise de como se dá a relação entre a rentabilidade e as variáveis específicas dos bancos ao longo do tempo, tendo em vista que as mudanças macroeconômicas podem exercer influência sobre o efeito destas características nos resultados dos bancos.

\section{REFERÊNCIAS}

Albertazzi, U., \& Gambacorta, L. (2009). Bank profitability and the business cycle. Journal of Financial Stability, 5(4), 393-409. https://doi.org/10.1016/j.jfs.2008.10.002

Banco Central do Brasil. (2014). Relatório de economia bancária e crédito. Banco Central do Brasil. Brasília, Brasil. http://www.bcb.gov.br/pec/depep/spread/rebc_2014.pdf

(2016). Relatório de estabilidade financeira. Relatório de Estabilidade Financeira, v. 15, n. 1, p. 1-78. http://www.bcb.gov.br/htms/estabilidade/2016_04/refPub.pdf

Bank for International Settlements. 85th BIS Annual Report 2014/2015. The 85th Annual General Meeting. Basel, Suíça, 2015. https://www.bis.org/publ/arpdf/ar2015_ec.pdf

Barreto, L. S., Pereira, V. S., \& Penedo, A. S. T. (2021). Impacto dos investimentos em tecnologia sobre a rentabilidade do setor bancário brasileiro. Future Studies Research Journal: Trends \& Strategies, 13(1), 94-111.

Chen, S. H., \& Liao, C. C. (2011). Are foreign banks more profitable than domestic banks? Home-and hostcountry effects of banking market structure, governance, and supervision. Journal of Banking \& Finance, 35(4), 819-839. https://doi.org/10.1016/j.jbankfin.2010.11.006

Ciganda, R. R. (2020). Fatores determinantes da rentabilidade bancária: uma aplicação de regressão quantílica para dados em painel. Mestrado em Economia, Insper.

Consumidor Moderno. (2021). A evolução das fintechs no Brasil: elas ganham cada vez mais espaço. Consumidor Moderno. https://www.consumidormoderno.com.br/2021/02/15/evolucao-fintechs-brasilganham-mais-espaco/

Dantas, J. A., Medeiros, O. R. D., \& Paulo, E. (2011). Relação entre concentração e rentabilidade no setor bancário brasileiro. Revista Contabilidade \& Finanças, 22(55), 5-28. http://dx.doi.org/10.1590/S1519-70772011000100002

Dietrich, A., \& Wanzenried, G. (2011). Determinants of bank profitability before and during the crisis: Evidence from Switzerland. Journal of International Financial Markets, Institutions and Money, 21(3), 307-327. https://doi.org/10.1016/j.intfin.2010.11.002

Dietrich, A., Hess, K., \& Wanzenried, G. (2014). The good and bad news about the new liquidity rules of Basel III in Western European countries. Journal of Banking \& Finance, 44, 13-25. https://doi.org/10.1016/j.jbankfin.2014.03.041

Elsas, R., Hackethal, A., \& Holzhäuser, M. (2010). The anatomy of bank diversification. Journal of Banking \& Finance, 34(6), 1274-1287. https://doi.org/10.1016/j.jbankfin.2009.11.024

Ferreira, J. H., Zanini, F. A., \& Alves, T. W. (2019). Bank revenue diversification: Its impact on risk and return in Brazilian banks. Revista Contabilidade \& Finanças, 30(79), 91-106. https://doi.org/10.1590/1808-057x201805810

García-Herrero, A., Gavilá, S., \& Santabárbara, D. (2009). What explains the low profitability of Chinese banks? Journal of Banking \& Finance, 33(11), 2080-2092. https://doi.org/10.1016/j.jbankfin.2009.11.024

Hannan, T. H., \& Prager, R. A. (2009). The profitability of small single-market banks in an era of multimarket banking. Journal of Banking \& Finance, 33(2), 263-271.

https://doi.org/10.1016/j.jbankfin.2008.07.018 
Hoffmann, P. R. S. (2011). Determinants of the profitability of the US banking industry. http://www.ijbssnet.com/journals/Vol_2_No_22_December_2011/30.pdf

Larghi, N. (2020). Número de fintechs no Brasil cresceu $28 \%$ no último ano, maioria é de pagamentos. Valor Investe. https://valorinveste.globo.com/objetivo/empreenda-se/noticia/2020/08/25/numero-defintechs-no-brasil-cresceu-28percent-no-ultimo-ano-maioria-e-de-pagamentos.ghtml

Lee, C. C., \& Hsieh, M. F. (2013). The impact of bank capital on profitability and risk in Asian banking. Journal of International Money and Finance, 32, 251-281. https://doi.org/10.1016/j.jimonfin.2012.04.013

Mirzaei, A., Moore, T., \& Liu, G. (2013). Does market structure matter on banks' profitability and stability? Emerging vs. advanced economies. Journal of Banking \& Finance, 37(8), 2920-2937. https://doi.org/10.1016/j.jbankfin.2013.04.031

Pereira, R. D. A. M. (2019). Rentabilidade bancária no Brasil: uma investigação empírica dos determinantes micro e macroeconômicos utilizando GMM. Dissertação de Mestrado em Economia, Insper

Primo, U. R., Dantas, J. A., Medeiros, O. R., \& Capelletto, L. R. (2013). Determinantes da rentabilidade bancária no Brasil. Revista Base (Administração e Contabilidade) da UNISINOS, 10(4), 308-323. https://doi.org/10.4013/base.2013.104.02

Rover, S., Tomazzia, E. C., \& Fávero, L. P. (2013). Financial and macroeconomic determinants of profitability: Empirical evidence from the Brazilian banking sector. Advances in Scientific and Applied Accounting, 6(2), 156-177. http://asaa.anpcont.org.br/index.php/asaa/article/view/96/85

Tabak, B. M., Fazio, D. M., \& Cajueiro, D. O. (2011). The effects of loan portfolio concentration on Brazilian banks' return and risk. Journal of Banking \& Finance, 35(11), 3065-3076. https://doi.org/10.1016/j.jbankfin.2011.04.006

Trujillo-Ponce, A. (2013). What determines the profitability of banks? Evidence from Spain. Accounting \& Finance, 53(2), 561-586. https://doi.org/10.1111/j.1467-629X.2011.00466.x

Vieira, C. A. M., \& Girão, L. F. D. A. P. (2016). Diversificação das receitas e risco de insolvência dos bancos brasileiros. Revista de Contabilidade e Organizações, 10(28), 3-17. http://dx.doi.org/10.11606/rco.v10i28.111758

Vinhado, F. S., \& Divino, J. A. (2013). Determinantes da rentabilidade das instituições financeiras no Brasil. Análise Econômica, 31(59). http://dx.doi.org/10.22456/2176-5456.23301 